\title{
Microstructure, mechanical and corrosion behaviors of AlCoCuFeNi-(Cr,Ti) high entropy alloys
}

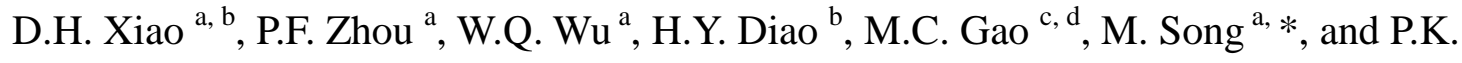 \\ $\operatorname{Liaw}^{\mathrm{b}, *}$ \\ ${ }^{a}$ State Key Laboratory of Powder Metallurgy, Central South University, Changsha 410083, China; \\ ${ }^{b}$ Department of Materials Science and Engineering, The University of Tennessee, Knoxville, TN 37996, \\ USA; \\ ${ }^{c}$ National Energy Technology Laboratory, Albany, OR 97321, USA; \\ ${ }^{d}$ AECOM, P.O. Box 1959, Albany, OR 97321, USA
}

\begin{abstract}
The equimolar AlCoCuFeNi-(Cr,Ti) HEAs were synthesized by nonconsumable arc melting to investigate the effects of $\mathrm{Cr}$ and $\mathrm{Ti}$ on the mechanical and corrosion properties of the HEAs. The results showed that as-cast AlCoCuFeNi-(Cr,Ti) HEAs have a multi-phase microstructure, of which the solid-solution face-centered cubic (FCC), body-centered cubic (BCC) phases, and intermetallics can be observed. Ab initio molecular-dynamics (AIMD) simulations exhibit the existence of the preferred short-range ordering of $\mathrm{Al}-\mathrm{Ni}, \mathrm{Co}-\mathrm{Cr}, \mathrm{Cr}-\mathrm{Fe}$, and Ti-Co pairs in the AlCoCuFeNiCrTi liquid structure. The AIMD simulations are consistent with the experimental observation during solidification. The segregations and the FCC Cu-rich phase appear in the AlCoCuFeNiCrTi alloy, which is in agreement with AIMD calculations. The $\mathrm{Cr}$ addition to AlCoCuFeNi facilitates the formation of the $\mathrm{BCC}$ phases in the AlCoCuFeNiCr alloy, which can be explained by the larger $\Omega$ and smaller $\delta$ values. The addition of large Ti atoms facilitates the formation of the FCC phase, which is due to the fact that Ti will easily induce the breakdown of the BCC solid-solution of the AlCoCuFeNi alloy in terms of decreasing the $\Omega$ value and increasing the $\delta$ value. The $\mathrm{Cr}$ addition improves the corrosion resistance of AlCoCuFeNi alloys.
\end{abstract}

Keywords: High entropy alloys; Chromium, Titanium; Microstructure; Properties

*Corresponding author. M. Song (msong@ @ csu.edu.cn); P.K. Liaw (pliaw@utk.edu) 


\section{Introduction}

Industry alloy systems are based on one or two principal elements to form the matrix, in the addition of minor alloying elements to improve mechanical behavior and other properties. As the amount of the minor alloying element increases, intermetallic compounds, which are normally hard and brittle, are usually formed. Although the strength of the alloys may further improve, the plasticity of the alloys often drops. In contrast, new unique materials, high-entropy alloys (HEAs), have been developed, which show and confirm their high strength/hardness [1-9], outstanding wear resistance [10, 11], exceptional fatigue and toughness [12-17] and low-temperature strength [17, 18], great structural stability [19], good corrosion resistance [20-22], and antioxidation [20-25].

HEAs, which were firstly proposed by Yeh et al. [1,6], are generally defined as those alloys containing at least five principal elements, each having the atomic percentage between 5\% and 35\%. Due to the high configurational entropy effect, especially at high temperatures, HEAs tend to form a simple solid solution, such as face-centered cubic (FCC) structure, body-centered cubic (BCC) structure, hexagonal close-packed (HCP) structure, or their mixtures [1-17, 26-28]. Even though extensive studies focus on the single-phase solid-solution HEAs, multi-phase HEAs are still promising [29]. There has been extensive research based on the Al-Co-Fe-Ni-Cr system [8, 9, 30-33] and $\mathrm{Al}-\mathrm{Co}-\mathrm{Cu}-\mathrm{Fe}-\mathrm{Ni}-\mathrm{Cr}$ system [3, 5, 11-14, 33-40]. The main difference between these systems is the presence of the Cu-rich phases in the latter. This is because $\mathrm{Cu}$ has positive mixing enthalpies with most of other elements, and, thus, is repelled to the inter-dendrite (IR) region $[5,12,34]$. Additionally, the remnant $\mathrm{Cu}$ in the dendrite region also clusters and forms various kinds of precipitates $[5,7,35,41]$. The researchers also found that the $\mathrm{Cu}$ element can enhance the FCC phase formation [37].

The additions of both $\mathrm{Cr}$ and $\mathrm{Ti}$ can affect the microstructures and properties of HEAs in various ways [12, 42-44]. However, there are some contradictory conclusions in the reported literatures. For example, Liu et al. [40] found that the $\mathrm{Cr}$ addition can improve the compressive strength and toughness, but reduce the ductility of $\mathrm{AlTiCr}_{x} \mathrm{FeCoNiCu}(x=0.5 \sim 2.5)$ HEAs prepared by the vacuum-arc furnace. However, $\mathrm{Fu}$ and the coworkers [41] reported that the $\mathrm{Cr}$ addition decreased the compressive strength and Vickers hardness of the twinned $\mathrm{CoFeNiAl}{ }_{0.5} \mathrm{Ti}_{0.5} \mathrm{Cr}$ alloy after the combination of mechanical alloying (MA) and spark-plasma sintering (SPS). Meanwhile, Chem et al. [12] reported that the Ti addition led to the formation of the CoCr-like phase and suppression of the $\mathrm{B} 2$ phase, and, thus, increased the hardness of the $\mathrm{Al}_{0.5} \mathrm{CoCrCuFeNiTi}_{x}(x=0 \sim 2.0)$ alloy. Zhou and the coworkers [9] studied the microstructure and mechanical properties of the $\mathrm{AlCoCrFeNiTi}_{x}(x=0 \sim 1.5)$ system at room temperature, and found that the 
alloy system is mainly composed of a simple BCC solid solution and showed excellent mechanical properties. Meanwhile, Qiu et al. [44] also found that the minor Ti element addition can enhance the corrosion resistance of $\mathrm{Al}_{2} \mathrm{CoCrCuFeNiTi}_{x}(x=0 \sim 2.0)$ coatings prepared by laser cladding in the 0.5 $\mathrm{mol} / \mathrm{L} \mathrm{HNO}_{3}$ solution.

Motivated by these previous investigations of the effects of the $\mathrm{Cr}$ and $\mathrm{Ti}$ additions on the microstructures and mechanical properties of multi-phase HEAs, in the current study, the as-cast AlCoCuFeNi-(Cr,Ti) HEAs with an equiatomic ratio were prepared, and, then, the alloying effect of $\mathrm{Cr}$ and $\mathrm{Ti}$ on the microstructures and properties of these alloys were investigated, using both experimental methods and computational simulations.

\section{Experimental procedures}

Four equiatomic ratio HEAs, including AlCoCuFeNi (I), AlCoCuFeNiCr (II), AlCoCuFeNiTi (III), and AlCoCuFeNiCrTi (IV), were prepared by the arc melting and casting method, where the purity of all components is greater than $99.9 \%$ (weight percent). Melting and casting were performed in a pure argon atmosphere and in a copper crucible. Repeated melting was carried out at least four times to improve the chemical homogeneity of the alloy $[3,5,6]$.

The crystalline structures of the ingots were identified via X-ray diffraction, using a Rigaku D/max 2550 diffractometer with $\mathrm{Cu} \mathrm{K}_{\alpha}$ radiation. Specimens cut from the ingots were polished and etched with aqua regia $\left(\mathrm{HNO}_{3}: \mathrm{HCl}=1: 3\right.$, volume fraction) for microstructure characterizations, using scanning-electron microscopy (SEM, FEI Nano SEM 230). The chemical compositions of the different phases were analyzed by the energy dispersive spectroscopy (EDS). Thin-foils specimens were prepared by conventional techniques of cutting, mechanically grinding, polishing, twin-jet elecropolishing, and, subsequently, were observed under a transmission-electron microscope (Tecnai G2 F20, FEI Company, Netherland) with the selected area electron diffraction (SAED) analysis. Hardness measurements were conducted, using a Vickers hardness tester (Micromets 5104) under a load of $50 \mathrm{~N}$ for $20 \mathrm{~s}$. Five random indents were made for each sample. Compression tests were performed on samples with a dimension of $\varphi$ $4 \mathrm{~mm} \times 8 \mathrm{~mm}$ using Instron 3369 testing machine at room temperature and at a strain rate of $1 \times 10^{-4} \mathrm{~s}^{-1}$. The tests were repeated three times. Fracture strength was measured by the maximum stress that a material can withstand during compression tests before breaking. After fracture, fracture strain is measured by the elongation over the gauge length using an extensometer, according the following equations: 


$$
\varepsilon_{f}=-\frac{L-L_{0}}{L_{0}}
$$

where $\mathrm{L}$ is the gauge length after fracture and $\mathrm{L}_{0}$ is the gauge length before compression tests.

Cylinder specimens with a dimension of $10 \mathrm{~mm}$ in diameter and $5 \mathrm{~mm}$ in length were used for the immersion-corrosion tests. These specimens were mounted in the epoxy resin with only one side being exposed as a working surface for immersion corrosion tests. These specimens were ground through 2000-grit SiC paper and polished using diamond grinding paste. Prior to immersed corrosion tests, each epoxy-prepared sample was weighed. The immersion corrosion tests were carried out in a $\mathrm{H}_{2} \mathrm{SO}_{4}$ solution with $0.5 \mathrm{M}$ (mol/L) $\mathrm{H}_{2} \mathrm{SO}_{4}$ solution plus water bath (XMTD-4000). The corrosion rates were investigated at two temperatures ( $298 \mathrm{~K}$ and $366 \mathrm{~K}$ ). The specimens were removed from the solution after immersion for $50 \mathrm{~h}$ and ultrasonically cleaned for 5 minutes in an alcohol solution to remove possible corrosion products. After rinsed in distilled water, these specimens were dried and weighed again. According to the actual weight loss of specimens, the average corrosion rates, by neglecting the weight loss of the mounting epoxy, were calculated using the following equation [45]:

$$
V=\frac{8.76 \times 10^{4} \times W}{t \times A \times D}
$$

where $W$ is the total weight loss (in g) after the exposure time, $t$ (in h), $D$ the density of the alloy (in $\mathrm{g} / \mathrm{cm}^{3}$ ), and $A\left(\right.$ in $\mathrm{cm}^{2}$ ) the surface area of the specimen.

The electrochemical experiments were conducted, using the CHI660C electrochemical test equipment at $298 \mathrm{~K}$ and $366 \mathrm{~K}$. The typical three-electrode electrochemical system consists of a platinum electrode as the counter electrode, and a saturated calomel electrode as the reference electrode. The HEAs samples were used as the working electrode with a surface of about $0.5 \mathrm{~cm}^{2}$ exposed to the $0.5 \mathrm{~mol} / \mathrm{L}$ $\mathrm{H}_{2} \mathrm{SO}_{4}$ solution. The polarization test was conducted by sweeping the potential from the cathode to anodic directions at a scan rate of $1 \mathrm{mV} / \mathrm{s}$. Each polarization experiment was run after holding the electrode for 1 minute at the open circuit potential to allow for a steady state to be achieved. The $0.5 \mathrm{~mol} / \mathrm{L} \mathrm{H}_{2} \mathrm{SO}_{4}$ and the three electrodes were put into the water bath to conduct tests at certain temperatures. The electrochemical tests were conducted at least three times to confirm a good reproducibility. Electrochemical characteristic parameters, such as corrosion potential $\left(\mathrm{E}_{\text {corr }}\right)$, corrosion current density $\left(\mathrm{i}_{\text {corr }}\right)$ can be derived from the potentiodynamic polarization curves by linear fitting at $298 \mathrm{~K}$ and $366 \mathrm{~K}$. In addition, the polarization resistances $\left(\mathrm{R}_{\mathrm{p}}\right)$ were calculated by means of the Stern-Geary equation according to $i_{\text {corr }}=\left(\beta_{\mathrm{a}} \times \beta_{\mathrm{c}}\right) /\left[2.3 \times \mathrm{R}_{\mathrm{p}}\left(\beta_{\mathrm{a}}+\beta_{\mathrm{c}}\right)\right]$, where $\beta_{\mathrm{a}}$ and $\beta_{\mathrm{c}}$ were the anodic and cathodic Tafel slopes that were obtained from polarization curves. Following the polarization experiment, the specimens were 
cleaned by ultrasonic washing and then dried in a drying cabinet. Subsequently, the morphology of the corroded surface of each specimen was examined by SEM.

\section{Ab initio molecular-dynamics (AIMD) simulations}

The computer simulation for the AlCoCuFeNiCrTi (IV) alloy was carried by the AIMD simulations, which were performed, using the plane-wave pseudo-potential software, Vienna Ab Initio Simulation Package (VASP) $[46,47]$ in a canonical ensemble, i.e., the constant mole, volume, and temperature, with the atomic-configuration relaxation and temperature controlled by a Nose thermostat [48]. Projector augmented-wave (PAW) potentials [49] and the revised Perdew-Burke-Ernzerhof [50] gradient approximation to the exchange-correlation functional were used. Cubic supercells of 196 atoms (a cell parameter of $13.7107 \AA$ ) was built for AlCoCrCuFeNiTi (IV) with a liquid density of $6.56 \mathrm{~g} / \mathrm{cm}^{3}$, which was determined by adjusting the cell volume so that the pressure was zero at equilibrium. The simulations were performed at the $\Gamma$ point only (i.e., the origin of the first Brillion zone), with a time step of 1 fs. A "medium" precision setting, as described in VASP, was used. Spin polarization was not considered. The electronic-energy-convergence criterion was set to the $1 \times 10^{-4} \mathrm{eV} / \mathrm{at}$. The AIMD simulations were performed with the plane-wave cutoff energy of $295.45 \mathrm{eV}$ at 2,073 $\mathrm{K}$ for a total simulation time of $30 \mathrm{ps}$. The atomic structure in the liquid state can reveal the useful information about the preferred interatomic bonding that may impact the formation of disordered solid solutions during solidification [5, 6, 51-53]. The partial pair distribution function (PDF) gives the information about the probability of such bond formation by measuring the intensity of near-neighbor pairs against the total random distribution, and partial PDF $\left(g_{a b}\right)$ was calculated, using:

$$
g_{a b}(r)=\frac{V}{N_{a} N_{B}} \frac{1}{4 \pi r^{2}} \sum_{i=1}^{N_{a}} \sum_{j=1}^{N_{b}}\left\langle\delta\left(\left|r_{i j}\right|-r\right)\right\rangle
$$

where $V$ is the volume of the supercell, $N_{a}$ and $N_{b}$ are the numbers of elements, $a$ and $b,\left|r_{i j}\right|$ is the distance between elements, $a$ and $b$, and the bracket, $\langle>$, denotes the time average of different configurations.

By examining the atomic trajectory, the diffusion constants were obtained by plotting the mean square displacement (MSD) versus time using the following equation:

$$
D_{i}=\lim _{t \rightarrow \infty} \frac{\left\langle\left|R_{i}(t)-R_{i}(0)\right|^{2}\right\rangle}{6 t}
$$

where $D_{i}$ is the self-diffusion constant of species, $i$, and $R_{i}(t)$ and $R_{i}(0)$ denote the atomic position of 
species, $i$, at time, $t$, and $t=0$, respectively. The angular brackets represent an average over all the same species.

\section{Results}

\subsection{Microstructures of as-cast HEAs}

The x-ray diffraction patterns of AlCoCuFeNi alloys with $\mathrm{Cr}$ or/and $\mathrm{Ti}$ additions are shown in Figure 1. Four alloys are composed of the FCC phase, disordered BCC phase (an A2 phase), and ordered BCC phase (a B2 phase), which were identified to be present in their microstructures (Table 1). The literatures reported that the equiatomic AlCoCuFeNi HEAs are composed of FCC and A2 phases [5, 6, 37]. When the Cr element was added, the dominant phases of the AlCoCuFeNiCr ( II) alloy switched to the BCC (A2, B2) phase, and the amount of the FCC phases obviously decreases. However, there are two FCC phases ["1" $\left(\mathrm{L1}_{2}\right)$ and "2" (FCC) phases] in the AlCoCuFeNiCr ( II) alloy. Two FCC phases are clearly visible from two overlapping peaks (Figure 1), corresponding to the two $\{111\}$ and $\{200\}$ planes with slightly-different lattice parameters. The similar phenomena were also reported in literatures [8, 54]. The XRD peak intensities of the AlCoCuFeNiTi (III) alloy suggest that the volume fraction of the FCC phase is higher than that of the A2 phase, which means that the Ti addition promotes the FCC formation and depresses the disordered $\mathrm{BCC}$ formation. Moreover, contrary to what was reported [12], no $\mathrm{Ti}_{2} \mathrm{Ni}-\mathrm{like}$ phases were identified in the AlCoCuFeNiTi (III) alloy. When both $\mathrm{Cr}$ and $\mathrm{Ti}$ are added, the peak intensity of the A2 phase in the AlCoCuFeNiCrTi (IV) alloy obviously increases, indicating the transition from the FCC to BCC phases. Figure 1 also shows that there are some small peaks of Laves phases in the alloys of AlCoCuFeNiTi (III) and AlCoCuFeNiCrTi (IV). It indicated that the Ti addition affected the solidification of the based alloys.

The lower and higher magnification SEM graphs of the as-cast AlCoCuFeNi-(Cr,Ti) alloys are shown in Figure 2. The chemical compositions of the alloys analyzed by EDS are summarized in Table 2. Due to the similar microstructure between the disordered BCC (A2) and ordered BCC (B2) phases, they cannot be obviously distinguished by SEM. The AlCoCuFeNi ( I ) alloy includes the FCC and BCC (A2/ B2) phases (Figures $2 \mathrm{a}$ and $2 \mathrm{~b}$ ). The regular FCC phases, which are $\mathrm{Cu}$-rich, are dispersed in the $\mathrm{AlCoCuFeNi}$ ( I ) alloy (bright in contrast). The BCC (A2/B2) phases have the high contents of $\mathrm{Al}$ and Ni elements (dark in contrast). With the additional $\mathrm{Cr}$, the morphology of the FCC phase further evolved into dendrites, while the BCC phase is converted into a lamella-like structure known as the 
Widmanstatten-side plates (Figures $2 \mathrm{c}$ and 2d) [8]. It indicates that the solidification mode of the AlCoCuFeNiCr ( II) alloy is affected by the Cr addition. The dendrites in the AlCoCuFeNiCr ( II) alloy are the $\mathrm{Cu}$-rich FCC phases. The Co-Ni-rich BCC phases are the heterogeneous nucleation on the surface of the $\mathrm{Cu}$-rich FCC phases. Meanwhile, the nano-sized basket precipitates in the $\mathrm{AlCoCuFeNiCr}(\mathrm{II})$ alloy have higher contents of $\mathrm{Al}$ and $\mathrm{Ni}$ elements than other regions (Figure 2d). These basket precipitates are identified to be the BCC phases [5]. After adding the Ti element, the microstructure of the AlCoCuFeNiTi (III) alloy consists of the coarse petal-shaped structure cell, and the cell size of $62 \mu \mathrm{m}$ is relatively large (Figures 2e and f). The petal-shaped structure cell includes the BCC phases (A2/B2), which are Al-, Co-, Ni-, and Ti-rich elements. The Al-Ni-rich BCC (A2/B2) and Cu-rich FCC phases are also observed in the AlCoCuFeNiTi (III) alloy. While adding both $\mathrm{Cr}$ and $\mathrm{Ti}$ to the AlCoCuFeNi HEA (Figures $2 \mathrm{~g}$ and $\mathrm{h}$ ), the petal-shaped structure cell size of the AlCoCuFeNiCrTi (IV) alloy is about $50 \mu \mathrm{m}$, and the microstructure was evidently refined, indicating that the $\mathrm{Cr}$ and $\mathrm{Ti}$ additions can promote the refinement of the grains of the as-cast alloys. Moreover, the $\mathrm{Cu}$ segregation becomes more evident (Figure 2h). The nano-sized spherical precipitates in the AlCoCuFeNiCrTi (IV) alloy are the Cr-Fe-rich BCC (A2/B2) phases. The Al-Ni-Ti-rich BCC phases are also observed in the AlCoCuFeNiCrTi (IV) alloy (Figure 2h).

Figure 3 shows the TEM micrographs and corresponding SAED patterns of the samples. Figure $3 a$ reveals the bright-field (BF) image of the AlCoCuFeNi ( I) alloy, and the corresponding SAED patterns of the FCC and disordered BCC (A2) phases. Figure $3 \mathrm{~b}$ indicates the $\mathrm{BF}$ image of the $\mathrm{AlCoCuFeNiCr}$ ( II) alloy and SAED patterns of the FCC and A2 phases. Meanwhile, Figures $3 \mathrm{c}$ and $3 \mathrm{~d}$ show the bright field (BF) images of the AlCoCuFeNiTi (III) and AlCoCuFeNiCrTi (IV) alloys and the corresponding SAED patterns of the FCC and BCC (A2/B2) phases.

\subsection{Liquid structures of AlCoCuFeNiCrTi (IV)}

The predicted partial PDF by the AIMD simulations is presented in Figure 4. All the partial PDFs show noticeable preference in the first-nearest-neighbor pairs, e.g., the $\mathrm{AlNi}, \mathrm{CoAl}, \mathrm{CoTi}, \mathrm{CuCu}$, and CrFe pairs. In contrast, the $\mathrm{AlAl}, \mathrm{CoCu}, \mathrm{CrCu}, \mathrm{CuFe}$, and TiTi pairs are among those least favorable pairs. The significant contrast in the partial PDFs indicates that the existence of the local chemical short-range order (SRO) in the liquid may intensify during solidification and serve as favorable nucleation embryo sites for crystalline phases [5]. As pointed by Gao and the coworkers [5, 6, 51, 55], a uniform PDF distribution suggests that the lack of SRO tends to favor solid solutions. Therefore, the predicted PDFs 
hint the formation of multi-phases in the as-cast state of the AlCoCuFeNi-(Cr,Ti) HEAs (Figure 2).

The MSD plot shown in Figure 5 demonstrates the linear behavior. The as-determined diffusion constants $\left(D_{o}\left[10^{-5} \mathrm{~cm}^{2} / \mathrm{s}\right]\right)$ are listed in Table 3. $D_{o}$ is the highest for $\mathrm{Ni}$, followed by $\mathrm{Cu}$, while it is the smallest for Ti that has the largest atomic size among the elements in the alloy.

\subsection{Mechanical properties and fracture-surface study}

Figure 6 shows the stress-strain curves of the investigated AlCoCuFeNi-(Cr,Ti) HEAs under compression at room temperature. The compression properties and Vickers hardnesses of the alloys are summarized in Table 4. The yield strength $\left(\sigma_{0.2}\right)$, fracture strength $\left(\sigma_{f}\right)$, fracture strains $\left(\varepsilon_{f}\right)$, Vickers hardness $(H V)$, and hardening coefficient $(n)$ of the AlCoCuFeNi ( I ) alloy are 1,060 MPa, 1,452 MPa, $19.1 \%, 387 \mathrm{HV}$, and 0.458 respectively. When the $\mathrm{Cr}$ element was added, the fracture strength and Vickers hardness of the AlCoCuFeNiCr ( I) alloy increase to $1,857 \mathrm{MPa}$ and $459 H V$, respectively. Meanwhile, the fracture strain and the hardening coefficient of the $\mathrm{AlCoCuFeNiCr}$ ( II) alloy are increased to $24.6 \%$ and 0.536 , respectively. The simultaneous appearance of the high strength and ductility is hardly seen in traditional metals and alloys. With the Ti addition, the strong work-hardening capabilities were observed in the alloys, AlCoCuFeNiTi (III) and AlCoCuFeNiCrTi (IV). The yield strengths of the AlCoCuFeNiTi (III) and AlCoCuFeNiCrTi (IV) alloys reach 1,612 $\mathrm{MPa}$ and 1,523 $\mathrm{MPa}$, respectively, significantly more than those of the AlCoCuFeNi ( I ) and AlCoCuFeNiCr ( II) alloys. The Vickers hardness of the AlCoCuFeNiTi (III) and AlCoCuFeNiCrTi (IV) alloys also increases to $623 H V$ and 510 $H V$, respectively. The hardening coefficients of the AlCoCuFeNiTi (III) and AlCoCuFeNiCrTi (IV) alloys are 0.414 and 0.455 , respectively. However, the $\mathrm{Ti}$ addition decreases the fracture strains of the AlCoCuFeNiTi (III) and AlCoCuFeNiCrTi (IV) alloys (Table 4). Moreover, the simultaneous addition of Ti and $\mathrm{Cr}$ elements also decreases the maximum strength of the AlCoCuFeNiCrTi (IV) alloy. Table 4 also shows that in the four alloys, the $\mathrm{AlCoCuFeNiCr}$ ( II) alloy has the highest hardening coefficient, while the AlCoCuFeNiTi (III) alloy has the lowest hardening coefficient, indicating that the $\mathrm{Cr}$ addition could improve the hardening coefficient, and the Ti addition could reduce the hardening coefficient.

The corresponding fractographic features were shown in Figure 7. Two typical fracture morphologies were observed for the $\mathrm{AlCoCuFeNi}$ ( I ) and $\mathrm{AlCoCuFeNiCr}$ ( II) alloys (Figures 7a and b). The fracture surfaces reveal the deformed and sheared regions. Moreover, the AlCoCuFeNiCr ( II) alloy exhibits the heavy deformation. It indicates that the fracture mode of the AlCoCuFeNiCr ( II) alloy is the 
ductile rupture. The fracture surfaces of the $\mathrm{AlCoCuFeNiTi}$ (II) and $\mathrm{AlCoCuFeNiCrTi}$ (IV) alloys (Figures $7 \mathrm{c}$ and $7 \mathrm{~d}$ ) consist of river-like patterns, indicating that the fracture morphology of the alloys exhibits the typical cleavage-fracture microstructures. Therefore, adding the Ti element is not beneficial to the ductility of HEAs (Table 4).

\subsection{Corrosion study}

The electrochemical-corrosion behavior of the as-cast alloys, which were immersed in a $0.5 \mathrm{~mol} / \mathrm{L}$ $\mathrm{H}_{2} \mathrm{SO}_{4}$ solution, was studied, using a potentiodynamic-polarization method. The polarization curves for the various alloys conducted at $298 \mathrm{~K}$ and $366 \mathrm{~K}$ are shown in Figure 8a and 8b, respectively. The measured values of the electrochemical parameters of the alloys are listed in Table 5. In Figure 8a, all of the four alloys have passivation regions and over passivation regions at $298 \mathrm{~K}$. While, the $\mathrm{AlCoCuFeNi}$ (I) has no passivation region when it was tested at $366 \mathrm{~K}$, indicating that the passivation film was damaged at $366 \mathrm{~K}$. All of the as-cast alloys conducted at $298 \mathrm{~K}$ have corrosion potentials $\left(\mathrm{E}_{\text {corr }}\right)$ in the range from 0.058 to $-0.256 \mathrm{~V}$ vs SCE. However, the alloys, $\mathrm{AlCoCuFeNi}$ ( I ) and $\mathrm{AlCoCuFeNiCr}$ (II), have the lower corrosion-current densities ( $\mathrm{i}_{\text {corr }}$ ) in the range of $5 \sim 8 \mu \mathrm{A} / \mathrm{cm}^{2}$, whereas the alloys, AlCoCuFeNiTi (III) and AlCoCuFeNiCrTi (IV) have the higher corrosion current densities in the range of $39 \sim 45 \mu \mathrm{A} / \mathrm{cm}^{2}$ at $298 \mathrm{~K}$.

The $\mathrm{AlCoCuFeNiCr}$ ( I) has a very high polarization resistance $\left(\mathrm{R}_{\mathrm{P}}\right)$ of $14,450.3 \Omega$, while other three alloys have a lower polarization resistance $\left(\mathrm{R}_{\mathrm{P}}\right)$ in the rage of $1,100 \sim 2,300 \Omega$ at $298 \mathrm{~K}$. After tested at $366 \mathrm{~K}$, the corrosion potentials ( $\mathrm{E}_{\text {corr }}$ ) of four alloys is from - 0.158 to $-0.368 \mathrm{~V}$ vs SCE. However, the $\mathrm{AlCoCuFeNi}$ ( I ) has a very low corrosion-current densities $\left(\mathrm{i}_{\text {corr }}\right)$ and high polarization resistance $\left(\mathrm{R}_{\mathrm{P}}\right)$ with the value of $11.74 \mu \mathrm{A} / \mathrm{cm}^{2}$ and $1,311.5 \Omega$, respectively. The other three alloys have the higher corrosion-current densities in the range of $779 \sim 3,380 \mu \mathrm{A} / \mathrm{cm}^{2}$ and the lower polarization resistance $\left(\mathrm{R}_{\mathrm{p}}\right)$ in the range of $29 \sim 36 \Omega$.

Figure 9 shows the SEM microstructure of the alloys after the potentiodynamic polarization in 0.5 mol/ $/ \mathrm{L} \mathrm{H}_{2} \mathrm{SO}_{4}$ at $298 \mathrm{~K}$. According to the SEM images, surface examinations showed that the major type of corrosion was pitting corrosion. The results of EDS indicated that the corroded areas have lower $\mathrm{Cu}$ contents, which indicated that the Cu-rich FCC phases in the alloys were mainly eroded during potentiodynamic polarization. However, the Al-, $\mathrm{Fe}-, \mathrm{Ni}-, \mathrm{Co}-$ and Ti-rich phases were retained.

Figure 10 presents the corrosion rate for the investigated alloys, which were immersed in a 0.5 $\mathrm{mol} / \mathrm{L} \mathrm{H}_{2} \mathrm{SO}_{4}$ solution at two different temperatures $(298 \mathrm{~K}$ and $366 \mathrm{~K})$. When the $\mathrm{Cr}$ element is added, 
the corrosion rate of the $\mathrm{AlCoCuFeNiCr}$ ( II) alloy is $0.048 \mathrm{~mm} /$ year, lower than that of the $\mathrm{AlCoCuFeNi}$ ( I ) alloy, which is $0.14 \mathrm{~mm} / \mathrm{year}$ at $298 \mathrm{~K}$. However, the corrosion rate of the AlCoCuFeNiCr ( II) alloy increases to $1.19 \mathrm{~mm} /$ year at $366 \mathrm{~K}$. With the Ti addition, the AlCoCuFeNiTi (III) alloy exhibits the higher corrosion rates, which are 27.16 and $32.20 \mathrm{~mm} / \mathrm{year}$ at $298 \mathrm{~K}$ and $366 \mathrm{~K}$, respectively. It indicates that the Ti addition decreases the corrosion resistance of the based alloys. When adding the $\mathrm{Cr}$ element, the corrosion rate of the $\mathrm{AlCoCuFeCrTi}(\mathrm{IV})$ alloy is lower than that of the AlCoCuFeNiTi (III) alloy.

\section{Discussion}

\subsection{Effects of $\mathrm{Cr}$ and $\mathrm{Ti}$ additions on the microstructures of the as-cast HEAs}

Figures 1, 2, and 3 show that the $\mathrm{Cr}$ and/or $\mathrm{Ti}$ additions affect the microstructures of HEAs significantly. The addition of the $\mathrm{Cr}$ element ( 16.7 at. \%) to AlCoCuFeNi (I) facilitates the formation of the $\mathrm{BCC}$ phase in the $\mathrm{AlCoCuFeNiCr}$ (II) alloy. It is different from the results of $\mathrm{Fu}$ and the coworkers [43], who thought that the addition of $\mathrm{Cr}(\sim 20$ at. $\%)$ to the $\mathrm{CoFeNiAl}_{0.5} \mathrm{Ti}_{0.5}$ alloy promoted the formation of the FCC phases. Meanwhile, the high magnified image shown in Figure 2d reveals the nano-scaled basket structure of the dendrite matrix. This basket structure can be regarded as the modulated plate resulting from the spinodal decomposition, which has been reported by Soffa and Laughlin [55]. Instead of the Cr addition, when Ti is added to the AlCoCuFeNi (I), the main phases in the AlCoCuFeNiTi (III) alloy are the FCC phases (Figures 1, 2e, and 2f). This trend indicates that the Ti addition ( 16.7 at. \%) promoted the formation of the FCC phases in AlCoCuFeNiTi (III). However, Qiu et al. [44] thought that the Ti addition, to a certain extent, promoted the formation of a BCC-dominant microstructure in $\mathrm{Al}_{2} \mathrm{CoCrFeNiCuTi}_{\mathrm{x}}$ coatings.

There are many factors, which may affect the microstructure of HEAs. According to the literatures, $\delta$ (the atomic-size parameter) $[4,6,56], \Delta S_{\text {conf }}$ (configurational entropy) $[1,4,6], \Delta x$ (the electronegativity difference) $[6,57], \operatorname{VEC}$ (valence electron concentration) $[6,58]$, and $\Omega$ (the parameter of the entropy of mixing times the average melting temperature of the elements divided by the enthalpy of mixing) $[6,56,59]$ are often selected to study the phase formation and stability of HEAs. The $\Delta S_{\text {conf }}$, which is the macroscopic - comprehensive reflection of the atomic-intrinsic characteristic, reflects the atomic-binding energy. It is related to the electronegativity difference $(\Delta \chi)$, electron density, etc. This is an important factor that affects the phase composition of HEAs. The atomic-size parameter $(\delta)$, which is adopted to describe the effect of the atom-size difference in the HEAs, also affects the phase compositions 
of HEAs. Moreover, the $V E C$ is the physical parameter to control the phase stability for FCC or BCC solid solutions.

The electronegativity difference $(\Delta \chi)$ of a HEA alloy is defined as follows [56]:

$$
\Delta \chi=\sqrt{\sum_{i=1}^{n} c_{i}\left(\chi_{i}-\bar{\chi}\right)^{2}}
$$

where $n$ is the number of the components in an alloy, $c_{i}$ is the molar fraction of the $i$-th component, $\chi_{i}$ is the Pauling electronegativity of the element, $i$, in the alloy, which can be obtained in Reference [60], and $\bar{\chi}=\sum_{i=1}^{n} c_{i} \chi_{i}$ is the mean value of the electronegativity for the alloy.

Meantime, the atomic-size parameter, $\delta$, is expressed as [4]:

$$
\delta=100 \sqrt{\sum_{i=1}^{N} c_{i} \times\left(1-r_{i} / \bar{r}\right)^{2}}
$$

where $n$ is the number of the components in an alloy, $c_{i}$ is the molar fraction of the $i$-th component, $r_{i}$ is the atomic radius, which can be obtained in Reference [60], and $\bar{r}\left(\sum_{i=1}^{n} c_{i} \times r_{i}\right)$ is the average atomic radius.

Let us consider an equiatiomic alloy in its liquid state or regular solid solution. Its ideal configuration entropy per mole can be calculated as follows $[1,4,6]$ :

$$
\Delta S_{\text {conf }}=R \ln n
$$

where $R$ is the gas constant, $8.314 \mathrm{~J} /(\mathrm{K} . \mathrm{mol})$, and $n$ is the number of the components in an alloy.

Moreover, the $V E C$ for the HEAs can be defined as follows [57, 58]:

$$
V E C=\sum_{i=1}^{n} c_{i} \times(V E C)_{i}
$$

where the $n$ is the number of the components in an alloy, $c_{i}$ is the molar fraction of the $i$-th component, and $(V E C)_{i}$ is the $V E C$ of the $i$-th element in an alloy.

The $\Omega$ parameter is introduced to predict the phase formation for HEAs. It represents the competition between the entropy and enthalpy, and can be calculated as follows $[6,56,59]$ :

$$
\Omega=\frac{T_{m} \Delta S_{m i x}}{\left|\Delta H_{m i x}\right|}
$$

where $T_{M}=\sum c_{i}\left(T_{m}\right)_{i}$ is the melting point of the alloy, $\Delta S_{m i x}=-R \sum c_{i} \ln c_{i}$ is the entropy of mixing, $\Delta H_{m i x}=\sum_{i<j} 4 c_{i} c_{j} \Delta H_{i j}^{m i x}$ is the enthalpy of mixing in the liquid, and $\Delta H_{i j}^{m i x}$ can be obtained in Reference [60].

According Equations (4) (8), the physical parameters of the present alloys are summarized in Table 1. The calculated $\delta$ values are 6.99 and 6.69 for the alloys AlCoCuFeNiTi (III) and $\mathrm{AlCoCuFeNiCrTi}(\mathrm{IV})$, respectively, which are higher than those (5.61\% and $5.19 \%)$ of the $\mathrm{AlCoCuFeNi}$ 
( I ) and $\mathrm{AlCoCuFeNiCr}$ (I) alloys (Table 1). A larger $\delta$ value is indicative of more severe lattice distortion. The $\mathrm{Cr}$ addition increases the $\Omega$ value to 5.06 and decreases the $\delta$ value to $5.19 \%$ for the AlCoCuFeNiCr ( II ) alloy, respectively. Zhang et al. $[6,56,59]$ thought that larger $\Omega(\geq 1.1)$ and smaller $\delta$ $(\leq 6.6 \%)$ should be expected to form the HEA-stabilized solid-solution phase. So the $\mathrm{Cr}$ addition promotes the formation of mainly the BCC solid-solution phase in the $\mathrm{AlCoCuFeNiCr}$ (II) alloy, compared to AlCoCuFeNi ( I ).

The atomic radius of $\mathrm{Ti}$ is the largest among $\mathrm{Fe}, \mathrm{Co}, \mathrm{Ni}, \mathrm{Cu}, \mathrm{Al}, \mathrm{Cr}$, and $\mathrm{Ti}[60]$, and, thus, will easily induce the breakdown of the BCC structure of the AlCoCuFeNi ( I ) alloy (Table 2). Table 1 also shows that the Ti addition decreases the $\Omega$ value from 3.53 to 1.43 and 1.95, and increases the $\delta$ value to $6.99 \%$ and $6.69 \%$ for the $\mathrm{AlCoCuFeNiTi}$ (III) and $\mathrm{AlCoCuFeNiCrTi}$ (IV) alloys. So the Ti addition results in the multiphase formation in the AlCoCuFeNiTi (III) and AlCoCuFeNiCrTi (IV) alloys (Figures 1 and 2). Figure 2 shows that the $\mathrm{Cu}$ segregation is the typical behavior in the AlCoCuFeNi-(Cr,Ti) HEAs. Since the mixing enthalpies for a mixture of $\mathrm{Cu}$ and each of $\mathrm{Co}, \mathrm{Fe}, \mathrm{Ni}$ and $\mathrm{Cr}$, are 6, 13, 4 and $12 \mathrm{~kJ} / \mathrm{mol}$ [56], respectively, $\mathrm{Cu}$ is rejected into the liquid during solidification, and, hence, $\mathrm{Cu}$-rich phases are formed in the regions (Figures 4 and 5). Figure 2 also presents that the Ti addition accelerates the $\mathrm{Cu}$ element to segregate and, thus, may result in the decrease of the ductility of HEAs (Table 4 and Figure 6).

Figure 4 suggests the existence of the preferred short-range ordering of $\mathrm{Al}-\mathrm{Ni}, \mathrm{Co}-\mathrm{Al}, \mathrm{Co}-\mathrm{Ti}, \mathrm{Cu}-\mathrm{Cu}$, and $\mathrm{Cr}-\mathrm{Fe}$ pairs in the liquid structure. These structural features in the liquid are consistent with the experimental observation of Al-Ni-rich, Cr-Fe-rich and Al-Ni-Ti-Co-rich phases (Figure 2 and Table 2) during solidification. The preferred $\mathrm{Cu}-\mathrm{Cu}$ pair correlation suggests that $\mathrm{Cu}$ tends to segregate in the liquid (Figure 4). This trend leads to the formation of a $\mathrm{Cu}$-rich phase during solidification, which is also consistent with the experimental observations (Figure 2).

\subsection{Effects of $\mathrm{Cr}$ and Ti additions on mechanical properties of as-cast HEAs}

Table 4 and Figure 6 show that the $\mathrm{Cr}$ addition can simultaneously improve the strength, hardening coefficient, and ductility of the based alloy. Figure 1 indicates that the volume fraction of BCC phases in the $\mathrm{AlCoCuFeNiCr}$ ( II) alloy is higher than that of the AlCoCuFeNi ( I ) alloy. The higher strength of the $\mathrm{AlCoCuFeNiCr}$ ( II) can be attributed to the solid-solution strength and strong bonding effect among the alloy metallic elements [61]. On the other hand, the nano-sized basket precipitates, BCC phases, can also enhance the strength of the $\mathrm{AlCoCuFeNiCr}$ (II) alloy. The high ductility may be attributed to the phase composition of the $\mathrm{AlCoCuFeNiCr}$ ( II) alloy. According to the basic structural factor, the structure with more slip systems leads to lower lattice friction during dislocation motion, and, thus, increases the 
ductility of the samples [62]. The FCC structure has slip planes with the closest packing, while the BCC structure has no true close-packed slip planes. Thus, the critical stress for slip in the FCC structure is basically smaller than that of the BCC structure. As the "2" FCC phase precipitates from the BCC matrix phase, the FCC phases can increase the ductility of the $\mathrm{AlCoCuFeNiCr}$ ( II) alloy.

The addition of the Ti element improves the mechanical properties of the AlCoCuFeNiTi, especial the yield strength and Vickers hardness, but decreases the ductility of the alloys 3 and 4 (Figure 6 and Table 4). It indicates that the strengthening effect of the $\mathrm{Ti}$ element is beyond the $\mathrm{Cr}$ element. The $\mathrm{Ti}$ addition was found to have significant influence on the refinement of grains and increase of the ferrite/pearlite ratio, and, hence, has significant effects on the mechanical properties and toughness of medium carbon steels [63].

\subsection{Effects of $\mathrm{Cr}$ and Ti additions on corrosion behavior of as-cast HEAs}

Figures 8 and 10 show that the $\mathrm{Cr}$ addition can generally improve the corrosion resistance of the AlCoCuFeNi ( I ) HEAs, but the Ti addition decreases the corrosion resistance of the base HEAs at 298 K. Due to the heterogeneous composition which is the common phenomenon in the arc melting and casting method, the microstructure (Figure 2), stress, micro-anode region, and micro-cathode region are formed in the electrolyte solution. The anode and cathode areas constitute the corrosion cell. Therefore, the alloys with two-phase structures are corroded easily, and the difference of electrode potentials is greater, the $\mathrm{i}_{\text {corr }}$ variation between the micro-anode and micro-cathode regions is larger. From the phase-structure analysis (Figures 1, 2, 3 and 9), the corrosion resistance of the BCC solid solution is better than that of the FCC solid solution in the $\mathrm{H}_{2} \mathrm{SO}_{4}$ liquid. This trend shows that the $\mathrm{AlCoCuFeNiCr}$ (II) alloy with the $\mathrm{Cr}$ addition has better corrosion resistance than other alloys at 298K. Meanwhile, $\mathrm{Cr}$ is easy to form $\mathrm{Cr}_{2} \mathrm{O}_{3}$, which being as a passivation film could prevent the HEAs further corrosion at $298 \mathrm{~K}$. However, $\mathrm{Cr}$ addition decreases the corrosion resistance of the base HEAs at 366K. That is because the $\mathrm{Cr}_{2} \mathrm{O}_{3}$ passivation film breaks down at a higher temperature, and the passivation film could not be regenerated, which could accelerate localized corrosion.

\section{Conclusions}

1) The as-cast AlCoCuFeNi-based HEAs are found to have a dendritic structure, in which only FCC and BCC solid-solution phases can be observed. The additions of $\mathrm{Ti}$ and $\mathrm{Cr}$ can refine the grains of the as-cast alloys, but result in the segregation of $\mathrm{Cu}$, and, thus, the formation of a FCC Cu-rich 
phase. The microstructure of the Ti-containing alloys is different from that of the Ti-free alloy.

2) The addition of the $\mathrm{Cr}$ element ( 16.7 at. \%) to AlCoCuFeNi facilitates the formation of the BCC solid solution in the AlCoCuFeNiCr alloy, which can be explained by the larger $\Omega$ and smaller $\delta$ values.

3) The addition of large Ti atom $(\sim 16.7$ at. \%) facilitates the formation of the FCC phase, which due to the fact that the Ti will easily induce the breakdown of the BCC solid-solution of the AlCoCuFeNi alloy in terms of decreasing the $\Omega$ value and increasing the $\delta$ value.

4) Preferred short-range ordering of $\mathrm{Al}-\mathrm{Ni}, \mathrm{Co}-\mathrm{Al}, \mathrm{Co}-\mathrm{Ti}, \mathrm{Cu}-\mathrm{Cu}$, and $\mathrm{Cr}-\mathrm{Fe}$ pairs exists in the liquid structure of the AlCoCuFeNiCrTi alloy. These structural features in the liquid are consistent with the experimental observation of the Al-Ni-rich, Cr-Fe-rich and Al-Ni-Ti-Co-rich phases during solidification. The preferred $\mathrm{Cu}-\mathrm{Cu}$ pair correlation suggests that $\mathrm{Cu}$ tends to segregate in the liquid.

5) The AlCoCuFeNi alloy with the $\mathrm{Cr}$ addition has the highest fracture strength of 1,857 $\mathrm{MPa}$, and the AlCoCuFeTi alloy has a high yield strength of 1,612 MPa. The addition of the Ti element increases the strength of $\mathrm{AlCoCuFeNi}$, which results from the introduced fine precipitates, like Laves phases.

6) The Ti addition decreases the corrosion resistance of the FeNiCoCuAl alloys at both $298 \mathrm{~K}$ and 366 $\mathrm{K}$, while the $\mathrm{Cr}$ addition improves the corrosion resistance of $\mathrm{AlCoCuFeNi}$ alloys without Ti.

\section{Acknowledgments}

D.H. Xiao and P.F. Zhou thank the support from the Natural Science Foundation of Hunan (CN) (No. 2016JJ214). M. Song thanks the supported from the State Key Laboratory of Powder Metallurgy at Central South University (CN). P.K. Liaw and H.Y. Diao thank the support from the Department of Energy (DOE), Office of Fossil Energy, National Energy Technology Laboratory (DE-FE-0008855 and DE-FE-0024054), with Mr. V. Cedro and Mr. R. Dunst as program managers. P.K.L. thanks the support from the project of DE-FE-0011194 with the program manager, Dr. J. Mullen. P.K.L. very much appreciates the support of the U.S. Army Research Office project (W911NF-13-1-0438) and the National Science Foundation Program (CMMI-11000 and DMR-1611180) with the program managers, Dr. D.M. Stepp, Dr. C. Cooper, and Dr. D.Farkas. M.C. Gao thanks the support from the Cross-Cutting Technologies Program of NETL under the RES contract DE-FE-0004000. Useful comments by anonymous reviewers are also acknowledged. 


\section{References}

1. J.W. Yeh, S.K. Chen, S.J. Lin, J.Y. Gan JY, T.S. Chin, T.T. Shun, C.H. Tsau, and S.Y. Chang, Nanostructured high-entropy alloys with multiple principal elements: novel alloy design concepts and outcome, Adv. Eng. Mater. 6 (2004) 299-303.

2. B. Cantor, I. Chang, P. Knight, A. Vincent, Microstructural development in equiatomic multicomponent alloys, Mater. Sci. Eng A. 375 (2004) 213-218.

3. O.N. Senkov, G.B. Wilks, D.B. Miracle, C.P. Chuang, P.K. Liaw, Refractory high-entropy alloys, Intermetallics 18 (2010) 1758-1765.

4. Y. Zhang, Y.J. Zhou, J.P. Lin, G.L. Chen, and P.K. Liaw, Solid-solution phase formation rules for multi-component alloys, Adv. Eng. Mater. 10 (2008) 534-538.

5. L.J. Santodonato, Y. Zhang, M. Feygenson, C.M. Parish, M.C. Gao, M.K. Miller, R.J. K. Weber, J.C. Neuefeind, Z. Tang, and P.K. Liaw, Deviation from high-entropy configurations in the atomic distributions of a multi-principal-element alloy, Nat. Commun. 6 (2014) 5964-5971.

6. Y. Zhang, T.T. Zuo, Z. Tang, M.C. Gao, K.A. Dahmen, P.K. Liaw, and Z.P. Lu, Microstructures and properties of high-entropy alloys, Prog. Mater. Sci. 61 (2014) 11-93.

7. O. Shigenobu, U. Yoshitaka, and K. Masanori, First-principles approaches to intrinsic strength and deformation of materials: perfect crystals, nano-structures, surfaces and interfaces, Modelling Simul. Mater. Sci. Eng. 17 (2009) 013001-5.

8. J.Y. He, W.H. Liu, H. Wang, Y. Wu, X.J. Liu, T.G. Nieh, and Z.P. Lu. Effects of Al addition on structural evolution and tensile properties of the FeCoNiCrMn high-entropy alloy system, Acta Mater. 62 (2014) 105-113.

9. Y.J. Zhou, Y. Zhang, Y.L.Wang, and G.L.Chen, Solid solution alloys of $\mathrm{AlCoCrFeNiTi}_{x}$ with excellent room-temperature mechanical properties, Appl. Phys. Lett. 90 (2007) 181904-181907.

10. M.H. Chuang, M.H. Tasi, W.R. Wang, S.J. Lin, and J.W. Yeh, Microstructure and wear behavior of $\mathrm{Al}_{\mathrm{x}} \mathrm{Co}_{1.5} \mathrm{CrFeNi}_{1.5} \mathrm{Ti}_{\mathrm{y}}$ high-entropy alloy, Acta Mater. 59 (2011) 6308-6317.

11. J.M. Wu, S.J. Lin, J.W. Yeh, S.K. Chen, and Y.S. Huang, Adhesive wear behavior of $\mathrm{Al}_{x} \mathrm{CoCrCuFeNi}$ high-entropy alloys as a function of aluminum content, Wear 261 (2006) 513-519.

12. M.R. Chem, S.J. Lin, J.W. Yeh, S.K. Chen, Y.S. Huang, and C.P. Tu, Microstructure and properties of $\mathrm{Al}_{0.5} \mathrm{CoCrCuFeNiTi}_{x}(x=0$ - 2.0) high-entropy alloys, Mater. Trans. 47 (2006) 1395-1401.

13. M. Seifi, D.Y Li, Y. Zhang, P.K. Liaw, and J.J. Lewandowski, Fracture toughness and fatigue crack growth behavior of as-cast high entropy alloys. JOM, 67 (2015) 2288-2295.

14. M.A. Hemphill, T. Yuan, G.Y. Wang, J.W. Yeh, C.W. Tsai, A. Chuang, and P.K. Liaw, Fatigue behavior of $\mathrm{Al}_{0.5} \mathrm{CoCrCuFeNi}$ high entropy alloys, Acta Mater. 60 (2012) 5723-5734.

15. Z. Tang, T. Yuan, C.W. Tsaid, J.W. Yeh, C.D. Lundina, and P.K. Liaw, Fatigue behavior of a wrought Al0.5CoCrCuFeNi two-phase high-entropy alloy. Acta Mater. 99 (2015) 247-258.

16. Z. Tang, M.C. Gao, H.Y. Diao, T.F.Yang, L.P. Liu, T.T. Zuo, Y. Zhang, Z.P. Lu, Y.Q.Cheng, W.Z. Zhang, K.A. Dahmen, P.K. Liaw, and T. Egami, Aluminum alloying effects on lattice types, microstructures, and mechanical behavior of high-entropy alloys systems, JOM. 65 (2013) 1848 -1858 .

17. B. Gludozatz, A. Hohenwater, D. Catoor, E.H. Chang, E.P. George, and R.O. Ritchie, A fracture-resistant high-entropy alloy for cryogenic applications, Science 345 (2014) 1153-1158. 
18. Z. Wu, H. Bei, G. M. Pharr, and E.P. George, Temperature dependence of the mechanical properties of equiatomic solid solution alloys with face-centered cubic crystal structures, Acta Mater. 81 (2014) 428-441.

19. Y.D. Wu, Y.H. Cai, and T. Wang, A refractory Hf25Nb25Ti25Zr25 high-entropy alloy with excellent structural stability and tensile properties, Mater. Letters. 130 (2014) 277-280.

20. X.W. Qiu, Y.P. Zhang, L.He, and C.G. Liu, Microstructure and corrosion resistance of AlCrFeCuCo high entropy alloy, J. Alloy. Compd. 549 (2013) 195-199.

21. Z.X. Liu, D.M. Li, L. Shi, B. Cai, and M.X. Wang, Corrosion behavior of CuCrFeNiMn high entropy alloy system in 1 M sulfuric acid solution, Mater. Corr. 63 (2012) 828-834.

22. Z. Tang, L. Huang, W. He, and P.K. Liaw, Alloying and processing effects on the aqueous corrosion behavior of high-entropy alloys, Entropy. 16 (2014) 895-911.

23. C. Huang, Y.Z. Zhang, J.Y. Shen, and R. Vilar, Thermal stability and oxidation resistance of laser clad TiVCrAlSi high entropy alloy coatings on Ti-6Al-4V alloy, Surf. Coat. Technol. 206 (2011) $1389-1395$.

24. O.N. Senkov, S.V. Senkova, D.M. Dimiduk, C. Woodward, and D.B. Miracle, Oxidation behavior of a refractory $\mathrm{NbCrMo}_{0.5} \mathrm{Ta}_{0.5} \mathrm{TiZr}$ alloy, J. Mater. Sci. 47 (2012) 6522-6534.

25. C.M. Liu, H.M. Wang, S.Q. Zhang, H.B. Tang, and A.L. Zhang, Microstructure and oxidation behavior of new refractory high entropy alloys, J. Alloy. Compd. 583 (2014) 162-169.

26. Y.J. Zhao, J.W. Qiao, S.G. Ma, M.C. Gao, H.J. Yang, M.W. Chen, Y. Zhang, A hexagonal close-packed high-entropy alloy: The effect of entropy, Materials \& Design, 96 (2016) 10-15.

27. M. Feuerbacher, M. Heidelmann, and C. Thomas, Hexagonal high-entropy alloys, Mater. Research Letters 3 (2014) 1-6.

28. M.C. Gao, B. Zhang, S.M. Guo, J.W. Qiao, and J.A. Hawk, High-entropy alloys in hexagonal close packed structure. Metall. Mater. Trans. A 47 (2016) 3322-3332.

29. D.B. Miracle, Critical Assessment 14: High entropy alloys and their development as structural materials, Mater. Sci. Technol. 31 (2015) 1142-1147.

30. T.T. Shun, and Y.C. Du, Microstructure and tensile behaviors of FCC $\mathrm{Al}_{0.3} \mathrm{CoCrFeNi}$ high entropy alloy, J. Alloys Compd. 479 (2009) 157-160.

31. W.R. Wang, W. L. Wang, S.C. Wang, Y.C. Tsai, C.H. Lai, and J.W. Yeh, Effects of Al addition on the microstructure and mechanical property of $\mathrm{Al}_{\mathrm{x}} \mathrm{CoCrFeNi}$ high-entropy alloys, Intermetallics 26 (2012) 44-51.

32. J. Chen, P. Y. Niu, Y.Z. Liu, Y.K. Lu, X.H. Wang, Y.L. Peng, J.N. Liu, Effect of Zr content on microstructure and mechanical properties of AlCoCrFeNi high entropy alloy, Materials \& Design 94 (2016) 39-44.

33. C.M. Lin, and H.L. Tsai, Evolution of microstructure, hardness, and corrosion properties of high-entropy $\mathrm{Al}_{0.5} \mathrm{CoCrFeNi}$ alloy, Intermetallics. 19 (2011) 288-295.

34. C.J. Tong, M.R. Chen, S.K. Chen, Y.W. Yeh, T.T. Shun, and S.Y. Chang, Microstructure characterization of $\mathrm{Al}_{\mathrm{x}} \mathrm{CoCrCuFeNi}$ high-entropy alloy system with multiprincipal elements, Metall. Mater. Trans. A 36 (2005) 881-893.

35. C. Ng, S. Guo, J. Luan, S. Shi, and C.T. Liu, Entropy-driven phase stability and slow diffusion kinetics in an $\mathrm{Al}_{0.5} \mathrm{CoCrCuFeNi}$ high entropy alloy, Intermetallics 31 (2012) 165-172. 
36. M.H. Tsai, H. Yuan, G. Cheng, W. Xu, K.Y. Tsai, C.W. Tsai, W.W. Jian, C.C. Juan, W.J. Shen, M.H. Chuang, J.W. Yeh, and Y.T. Zhu, Morphology, structure and composition of precipitates in $\mathrm{Al}_{0.3} \mathrm{CoCrCu}_{0.5} \mathrm{FeNi}$ high-entropy alloy, Intermetallics 32 (2013) 329-336.

37. C.C. Tung, J.W. Yeh, T.T. Shun, S.K. Chen, Y.S. Huang, and H.C. Chen, On the elemental effect of AlCoCrCuFeNi high-entropy alloy system, Mater. Lett. 61 (2007) 1-5.

38. K.B. Zhang, Z.Y. Fu, J.Y. Zhang, J. Shi, W.M. Wang, H. Wang, Y.C. Wang, and Q.J. Zhang, Annealing on the structure and properties evolution of the $\mathrm{CoCrFeNiCuAl}$ high-entropy alloy, $\mathrm{J}$. Alloys Compd. 502 (2010) 295-299.

39. A.V. Kuznetsov, N.D. Stepanov, G.A. Salishchev, and O.N. Senkov, Tensile properties of an $\mathrm{AlCrCuNiFeCo}$ high-entropy alloy in as-cast and wrought conditions, Mater. Sci. Eng. A 533 (2012) 107-108.

40. Z.Y. Liu, S. Guo, X.J. Liu, J.C. Ye, Y. Wang, X.L. Wang, L. Yang, K. An, and C.T. Liu, Micromechanical characterization of casting-induced inhomogeneity in an $\mathrm{Al}_{0.8} \mathrm{CoCrCuFeNi}$ high-entropy alloy, Scr. Mater. 64 (2011) 868-875.

41. C.W. Tsai, Y.L. Chen, M.H. Tsai, J.W. Yeh, T.T. Shun, and S.K. Chen, Deformation and annealing behaviors of high-entropy alloy $\mathrm{Al}_{0.5} \mathrm{CoCrCuFeNi}$, J. Alloys Compd. 486 (2009) 427-435.

42. A.M. Li, D. Ma, and Q.F. Zheng, Effect of $\mathrm{Cr}$ on microstructure and properties of a series of

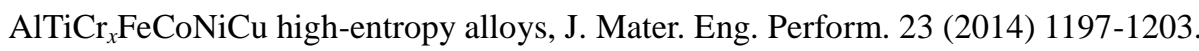

43. Z.Q. Fu, W.P. Chen, S. C. Fang, and X.M. Li, Effect of $\mathrm{Cr}$ addition on the alloying behavior, microstructure and mechanical properties of twinned $\mathrm{CoFeNiAl}_{0.5} \mathrm{Ti}_{0.5}$ alloy, Mater. Sci. Eng. A 597 (2014) 204-211.

44. X.W. Qiu, Y.P. Zhang, and C.G. Liu, Effect of Ti content on structure and properties of $\mathrm{Al}_{2} \mathrm{CrFeNiCoCuTi} i_{x}$ high-entropy alloy coatings, J. Alloys Compd. 585 (2014) 282-286.

45. ASTM Standard G31-72, ASTM, PA, 2004.

46. G. Kresse, J. Hafner, Ab initio molecular dynamics for liquid metals, Phys. Rev. B 47 (1993) 558-561.

47. G. Kresse, J. Furthmüller, Efficient iterative schemes for ab initio total-energy calculations using a plane-wave basis set, Phys. Rev. B 54 (1996) 11169-11186

48. S. Nose, Unified formulation of the constant temperature molecular dynamics methods, J. Chem. Phys. 81 (1984) 511-519.

49. P.E. Blochl, Projector augmented-wave method, Phys. Rev. B 50 (1994) 17953-17979.

50. J.P. Perdew, A. Ruzsinszky, G.I. Csonka, O.A. Vydrov, G.E. Scuseria, L.A. Constantin, X.L. Zhou, and K. Burke, Restoring the density-gradient expansion for exchange in solids and surfaces, Phys. Rev. Lett., 100 (2008) 039902-5.

51. M.C. Gao, D.E. Alman, Searching for next single-phase high-Entropy alloy compositions, Entropy 15 (2013) 4504-4519.

52. P. Ganesh, M. Widom, Ab initio simulations of geometrical frustration in supercooled liquid Fe and Fe-based metallic glass, Phys. Rev. B 77 (1): 014205-208.

53. S. Singh, N. Wanderka, B.S. Murty, U. Glatzel, J. Banhart, Decomposition in multi-component AlCoCrCuFeNi high-entropy alloy, Acta Mater. 59 (2011) 182-190.

54. M.C. Gao, J.W. Yeh, .P.K. Liaw and Y. Zhang, High-Entropy Alloys: Fundamentals and Applications. 
Cham, Switzerland: Springer International Publishing, 2016. (doi: 10.1007/978-3-319-27013-5).

55. W.A. Soffa, D.E. Laughlin, Proc. Int. on Solid-Solid Phase Transformation, Pittsburgh. PA, August 10-14, ASM, Metals Park, OH, 1981, pp. 159-182.

56. X. Yang, Y. Zhang, Prediction of high-entropy stabilized solid-solution in multi-component alloys, Mater. Chem. Phys. 132 (2012) 233-238.

57. S.S. Fang, X. Xiao, X. Lei, W.H. Li, and Y.D. Dong, Effect of valence electron concentration on stability of FCC or BCC phase in high entropy alloys, J. Non-cryst. Solids 321 (2003) 93-100.

58. S. Guo, C.Ng, J. Lu and C.T. Liu, Effect of valence electron concentration on stability of fcc or bcc phase in high entropy alloys, J. Appl. Phys. 109 (2011) 103505-4.

59. Y. Zhang, Z.P. Lu, S.G. Ma, P.K. Liaw, Z. Tang, Y.Q. Cheng, and M.C. Gao, Guidelines in predicting phase formation of high-entropy alloys, MRS Commun. 4 (2014) 57-62.

60. WebElements: the periodic table on the web, available at: http: // www.webelements.com.

61. A. Takeuchi, A. Inoue, Calculations of mixing enthalpy and mismatch entropy ternary amorphous alloys. Mater. Trans. JIM 41 (2000) 1372-1378.

62. J.J. Harwood, Proceedings of the ASM Seminar: Strengthening Mechanisms in Solids, Metals Park, OH, 1960, p. 23.

63. H.S. El-Faramawy, S.N. Ghali, and M.M. Eissa, Effect of titanium addition on behavior of medium carbon steel, J. Mine. Mater. Charact. Eng. 11 (2012) 1108-1112. 


\section{List of Tables}

Table 1. Compositions and physical parameters of the alloys

Table 2. Nominal compositions of HEAs and chemical compositions (at. \%) of different areas from

Figure 2

Table 3. Predicted diffusion constants of AlCoCuFeNiCrTi (IV) at $\mathrm{T}=2,073 \mathrm{~K}$.

Table 4. Mechanical properties of as-cast alloys.

Table 5. Dynamic parameters derived from the potentiodynamic-polarization curves by linear fitting at $298 \mathrm{~K}$ and $366 \mathrm{~K}$. 


\section{Figure captions}

Figure 1. XRD graphs of as-cast alloys.

Figure 2. SEM graphs of as-cast $\mathrm{AlCoCuFeNi}$ ( I ) (a, b), $\mathrm{AlCoCuFeNiCr}$ ( II ) (c, d), $\mathrm{AlCoCuFeNiCr}$ (III) (e, f), and AlCoCuFeNiCrTi (IV) (g, h).

Figure 3. TEM bright-field images and corresponding SAED patterns of the samples.
(a) $\mathrm{AlCoCuFeNi}$ ( I ),
(b) $\mathrm{AlCoCuFeNiCr}$ ( II ),
(c) AlCoCuFeNiTi (III), and
(d)

\section{$\mathrm{AlCoCuFeNiCrTi}(\mathrm{IV})$}

Figure 4. Predicted partial pair distribution function of $\mathrm{AlCoCuFeNiCrTi}$ (IV) pertaining to (a) Al, (b) Co, (c) $\mathrm{Cu},(\mathrm{d}) \mathrm{Fe},(\mathrm{e}) \mathrm{Ni}$, (f) $\mathrm{Cr}$, and (g) $\mathrm{Ti}$ at $\mathrm{T}=2,073 \mathrm{~K}$.

Figure 5. Predicted mean square displacement of AlCoCuFeNiCrTi (IV) at $\mathrm{T}=2,073 \mathrm{~K}$.

Figure 6. The engineering stress-strain curves of as-cast alloys at the room-temperature.

Figure 7. SEM graphs of the fracture samples. (a) AlCoCuFeNi ( I ), (b) $\mathrm{AlCoCuFeNiCr}$ ( II), (c) AlCoCuFeNiTi (III), and (d) AlCoCuFeNiCrTi (IV).

Figure 8. Potentiodynamic-polarization curves of as-cast alloys in the $0.5 \mathrm{~mol} / \mathrm{L} \mathrm{H}_{2} \mathrm{SO}_{4} \mathrm{H}$ solution at 298 $\mathrm{K}$ and $366 \mathrm{~K}$.

Figure 9. Surface images of as-cast alloys after potentiodynamic polarization in the $0.5 \mathrm{~mol} / \mathrm{L} \mathrm{H}_{2} \mathrm{SO}_{4}$.
(a) $\mathrm{AlCoCuFeNi}$
( I ),
(b) $\mathrm{AlCoCuFeNiCr}$ ( II ),
(c) AlCoCuFeNiTi
(III), and
(d)

\section{$\mathrm{AlCoCuFeNiCrTi}$ (IV).}

Figure 10. The corrosion rate for as-cast alloys in the $0.5 \mathrm{~mol} / \mathrm{L} \mathrm{H}_{2} \mathrm{SO}_{4}$ solution plus bath at $298 \mathrm{~K}$ (a) and $366 \mathrm{~K}(\mathrm{~b})$. 


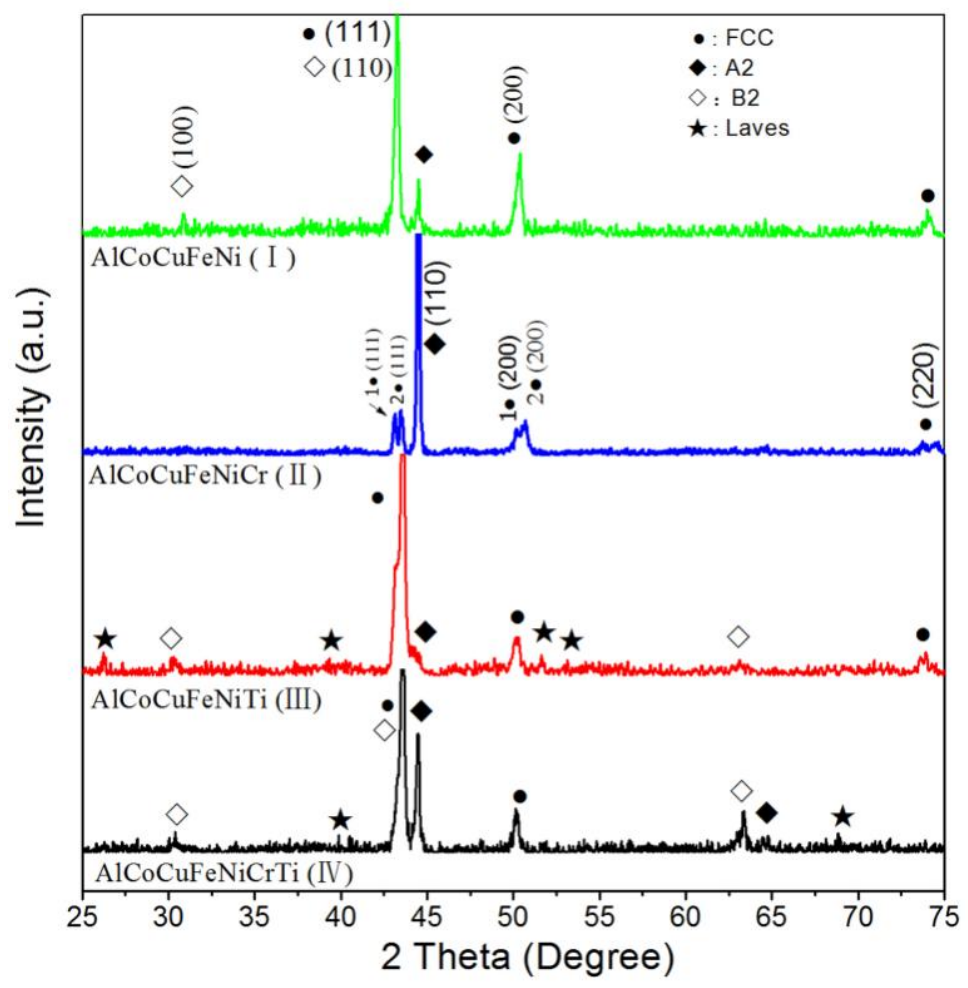



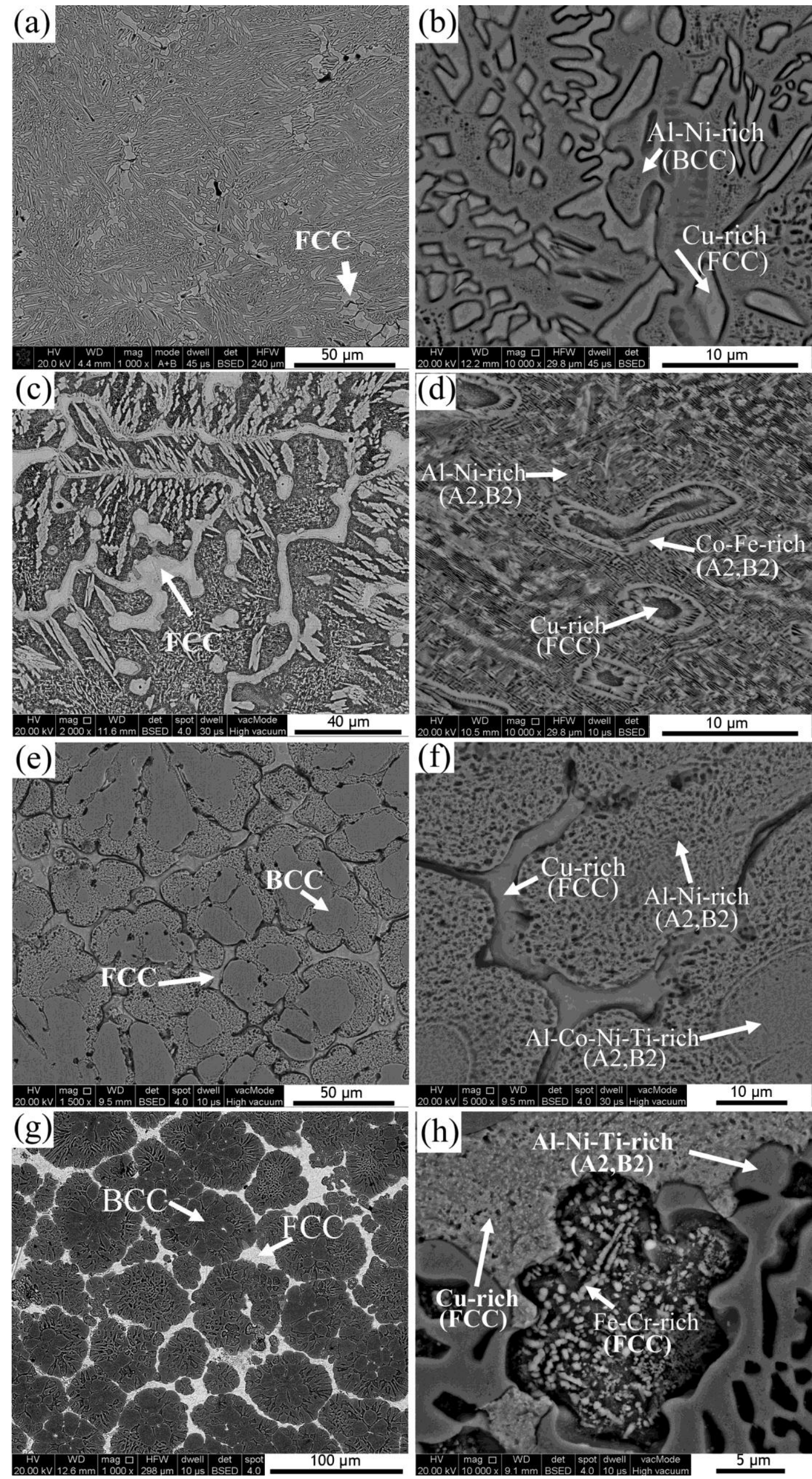


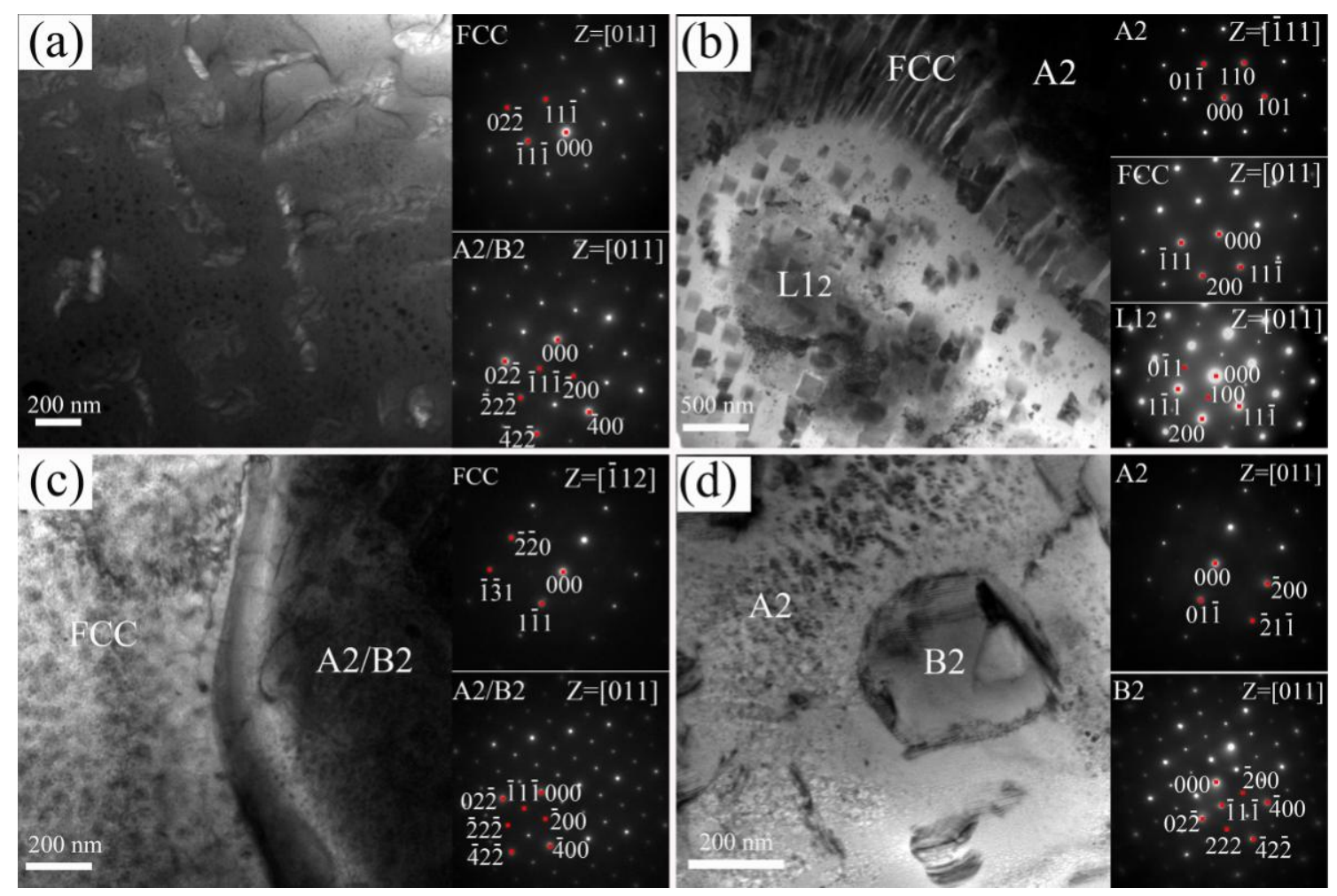




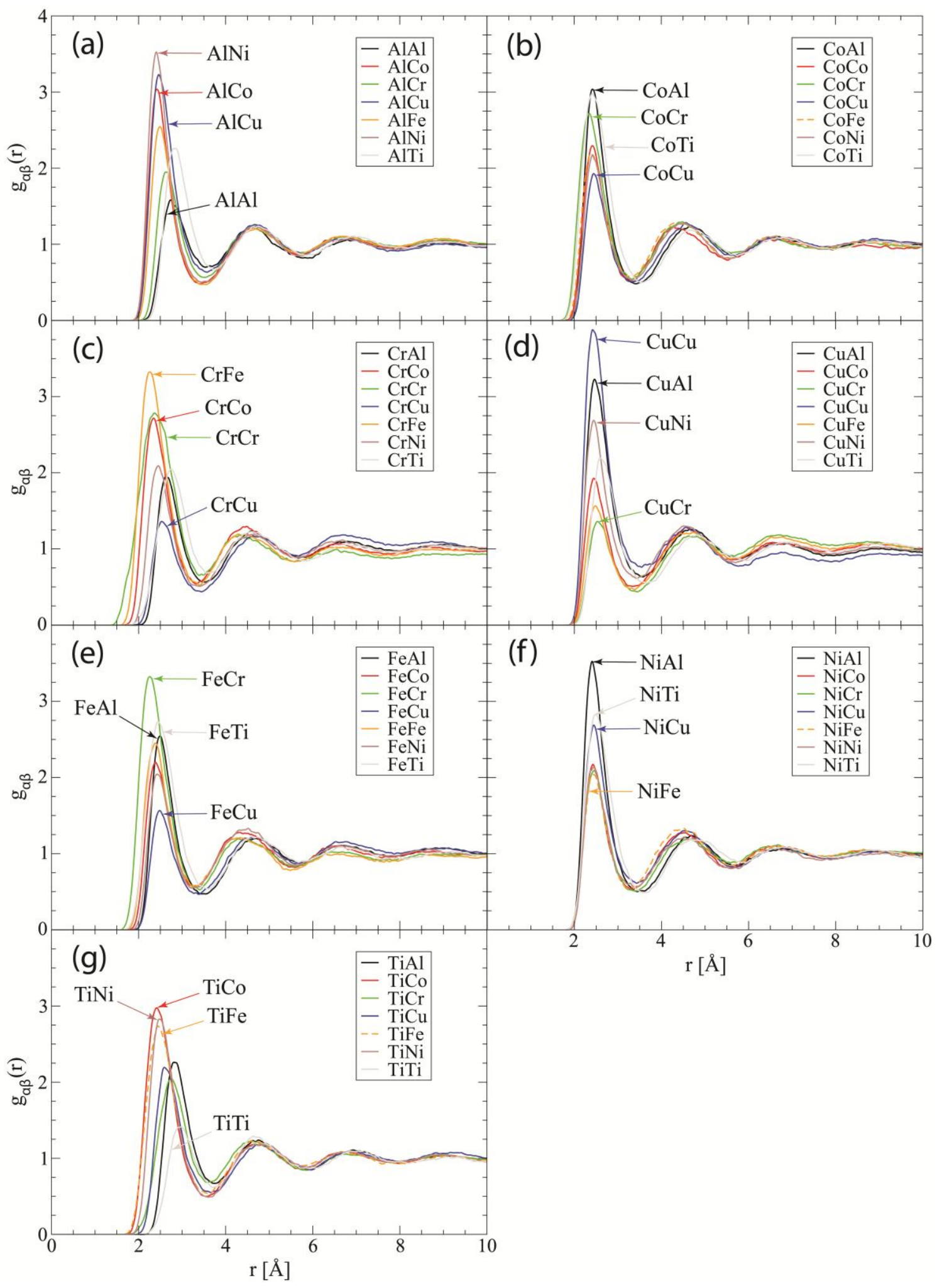




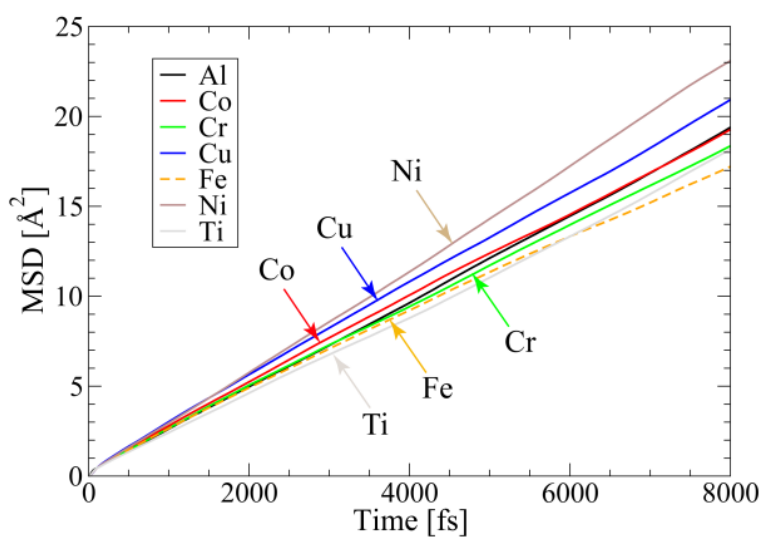




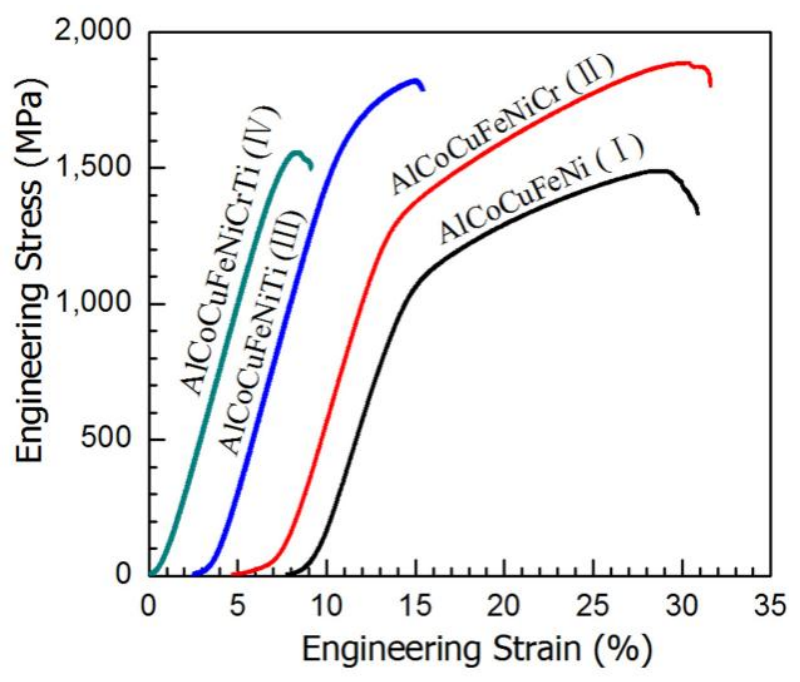



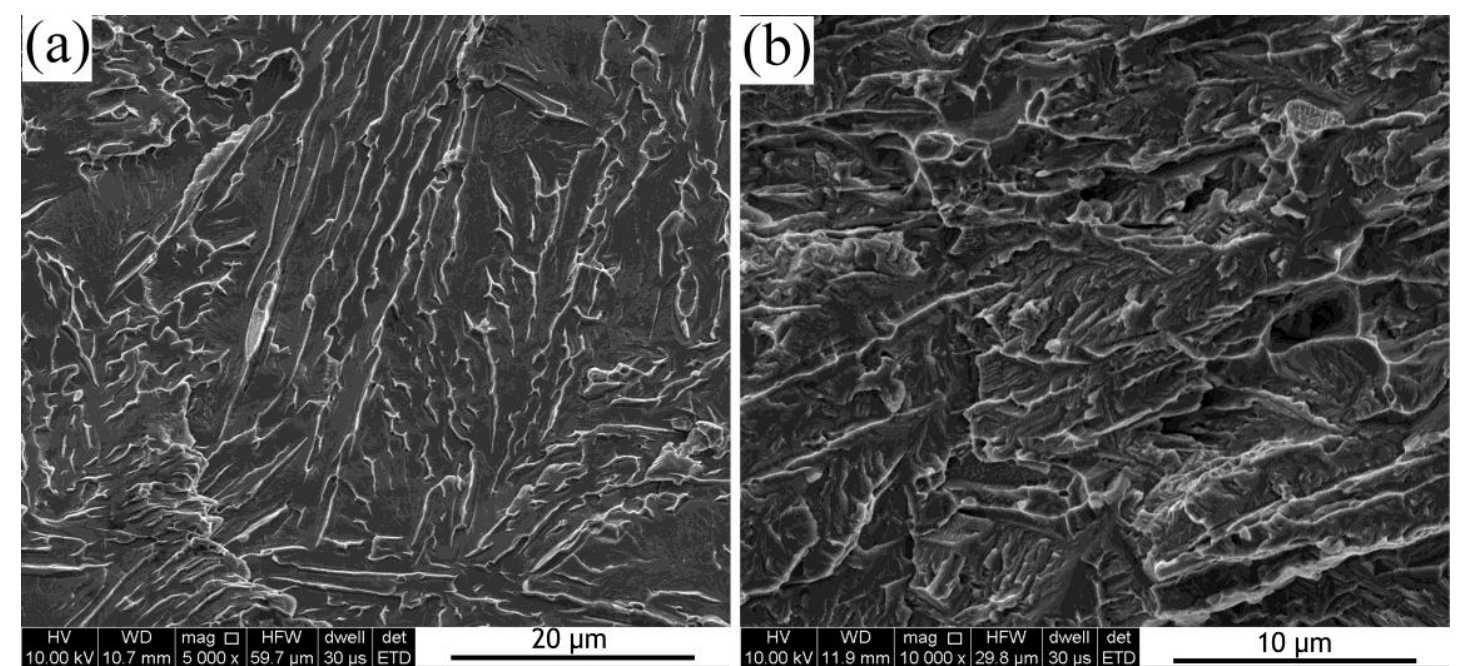

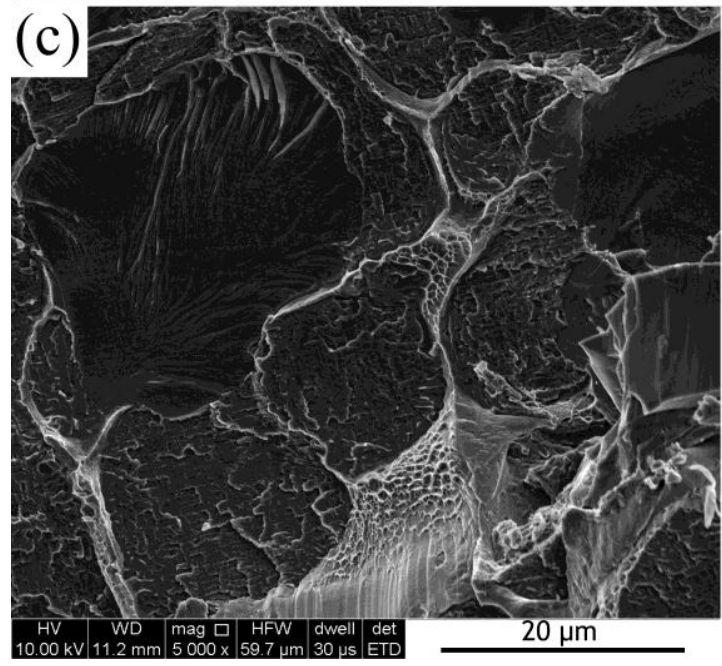

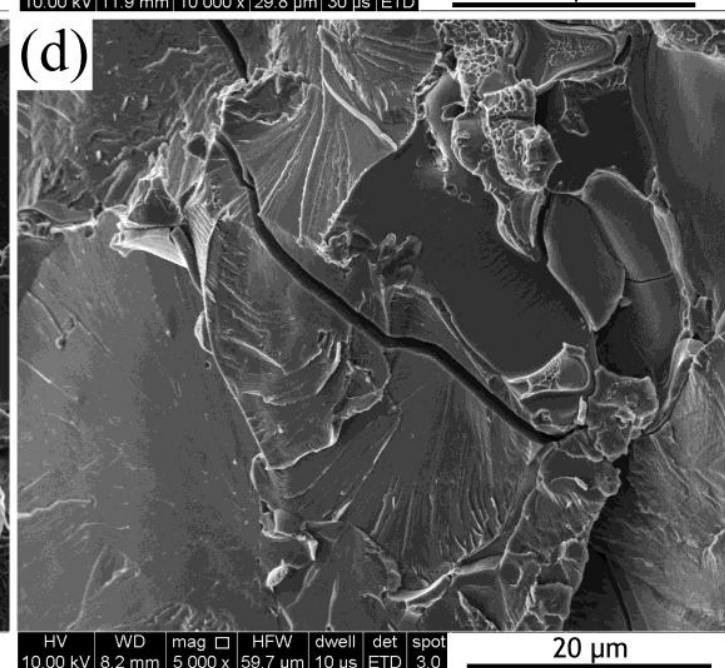



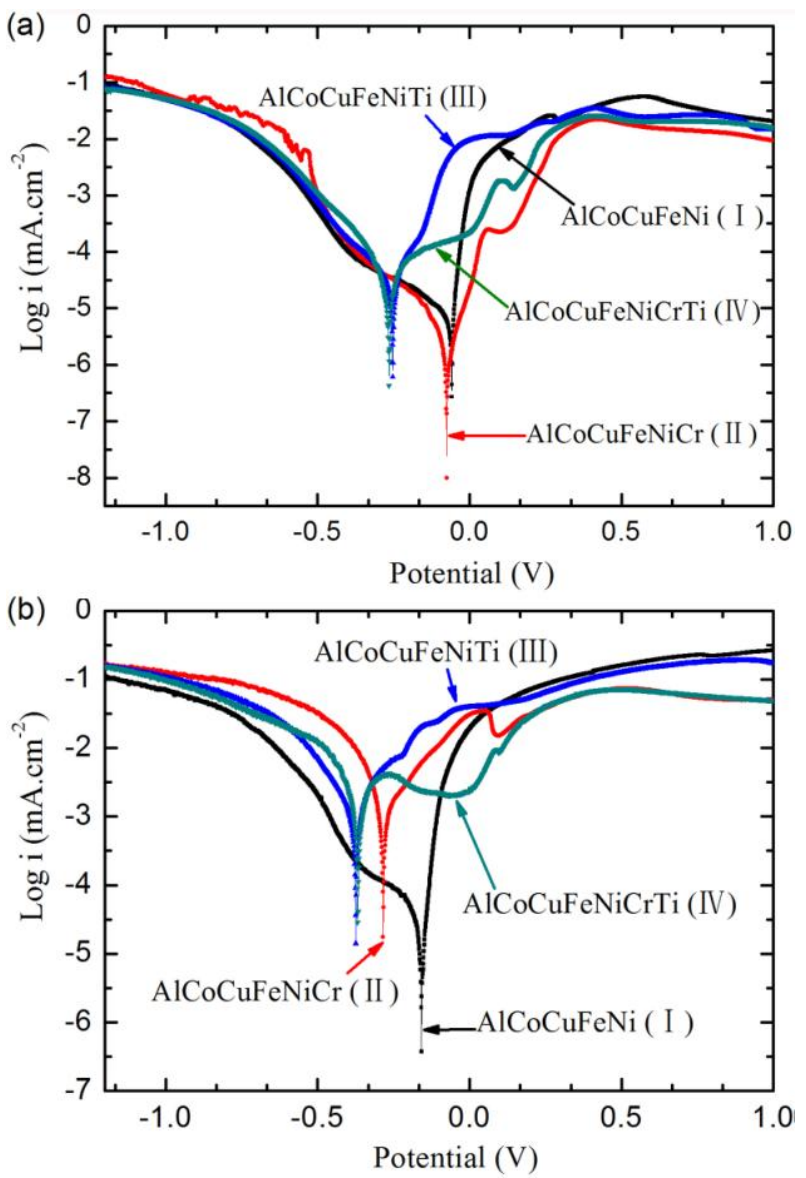

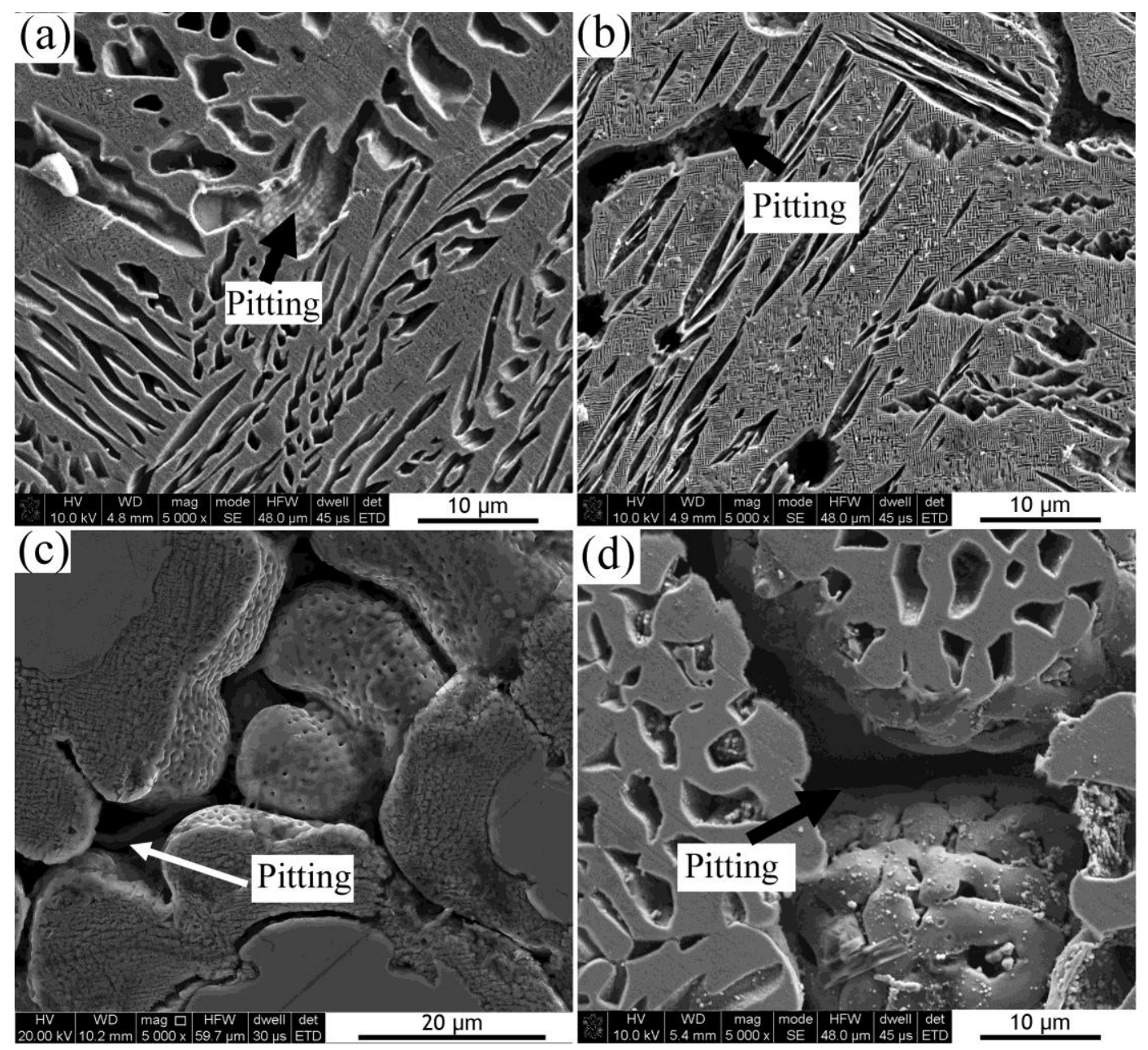

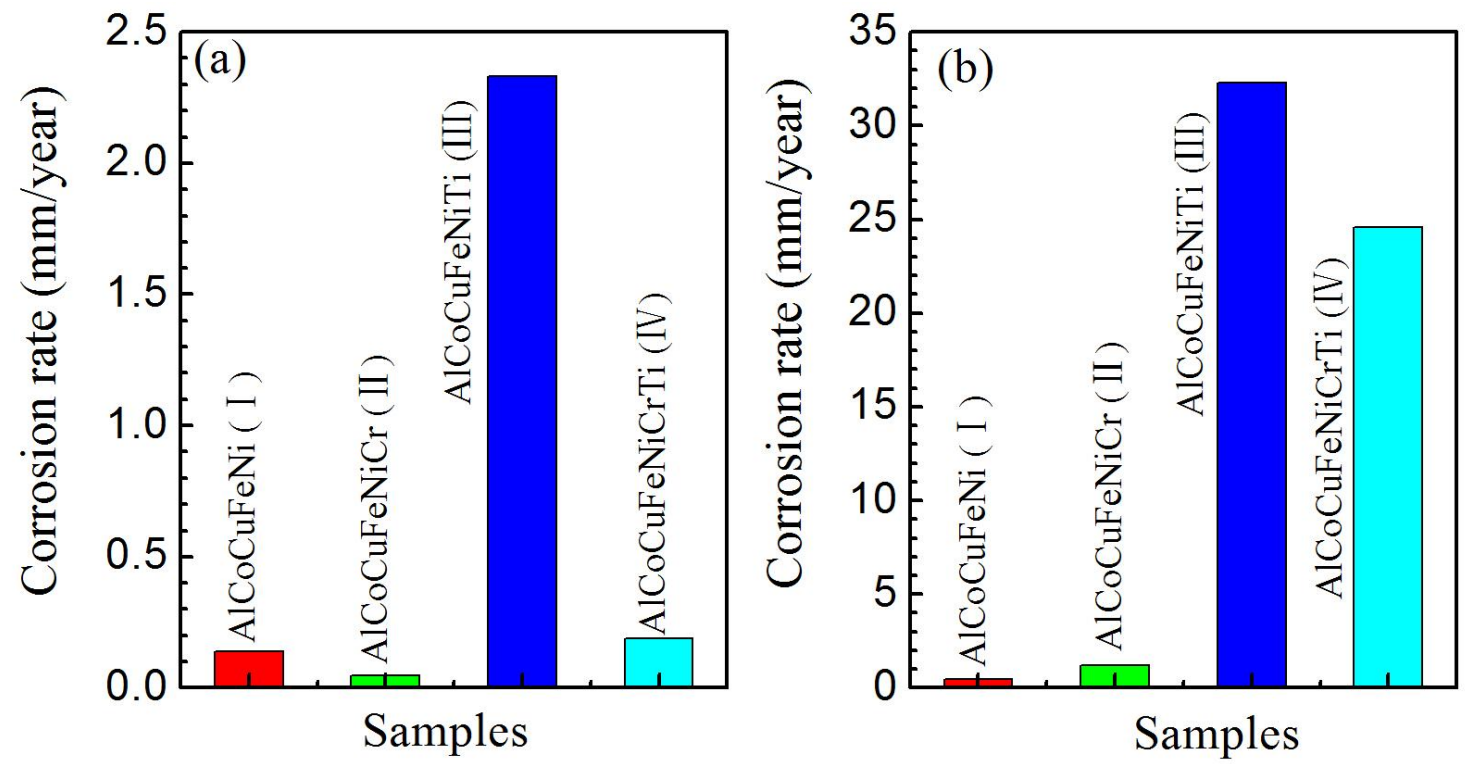
Table 1. Compositions and physical parameters of the alloys

\begin{tabular}{|c|c|c|c|c|c|c|c|c|}
\hline Sample & Phase composition & $\begin{array}{c}\triangle S_{\text {conf }} \\
(\mathrm{J} \cdot \mathrm{mol}-1 \cdot \mathrm{K}-1)\end{array}$ & $\begin{array}{c}\triangle H_{\text {mix }} \\
(\mathrm{kJ} \cdot \text { mol-1) }\end{array}$ & $\Omega$ & $\overline{V E C}$ & $\delta \quad(\%)$ & $\Delta x$ & $\triangle T \quad(\mathrm{~K})$ \\
\hline $\mathrm{AlCoCuFeNi}(\mathrm{I})$ & $\mathrm{FCC}+\mathrm{A} 2 / \mathrm{B} 2$ & 13.38 & -5.76 & 3.53 & 8.20 & 5.61 & 0.130 & 16.0 \\
\hline $\mathrm{AlCoCuFeNiCr}$ ( II) & $\mathrm{A} 2 / \mathrm{B} 2+\mathrm{FCC}$ & 14.90 & -4.78 & 5.06 & 7.83 & 5.19 & 0.138 & 15.8 \\
\hline AlCoCuFeNiTi (III) & $\mathrm{FCC}+\mathrm{A} 2 / \mathrm{B} 2+$ Laves & 14.90 & -16.56 & 1.43 & 7.50 & 6.99 & 0.165 & 23.6 \\
\hline AlCoCuFeNiCrTi (IV) & $\mathrm{FCC}+\mathrm{A} 2 / \mathrm{B} 2+$ Laves & 16.18 & $\begin{array}{ll}-13.8 \\
-1\end{array}$ & 1.95 & 7.29 & 6.69 & 0.155 & 21.7 \\
\hline
\end{tabular}


Table 2 Nominal compositions of HEAs and chemical composition (at. \%) of different areas from Figure 2

\begin{tabular}{|c|c|c|c|c|c|c|c|c|c|}
\hline Sample & Composition & Crystal structure & $\mathrm{Al}$ & Co & $\mathrm{Cu}$ & $\mathrm{Fe}$ & $\mathrm{Ni}$ & $\mathrm{Cr}$ & $\mathrm{Ti}$ \\
\hline & Nominal composition & - & 20 & 20 & 20 & 20 & 20 & - & - \\
\hline \multirow[t]{3}{*}{ AlCoCuFeNi ( I ) } & $\mathrm{Cu}-\mathrm{Co}-\mathrm{Fe}-$ rich & FCC & 12.65 & 20.38 & 25.86 & 22.38 & 18.73 & - & - \\
\hline & Al-Ni-rich & $\mathrm{BCC}(\mathrm{A} 2 / \mathrm{B} 2)$ & 24.56 & 21.56 & 11.37 & 19.65 & 22.87 & - & - \\
\hline & Nominal composition & - & 16.67 & 16.67 & 16.67 & 16.67 & 16.66 & 16.66 & - \\
\hline \multirow[t]{4}{*}{$\mathrm{AlCoCuFeNiCr}$ (II ) } & $\mathrm{Cu}$-rich & FCC & 11.31 & 15.60 & 29.31 & 14.58 & 17.52 & 11.67 & - \\
\hline & Al-Ni-rich & $\mathrm{BCC}(\mathrm{A} 2 / \mathrm{B} 2)$ & 25.58 & 16.82 & 10.91 & 14.27 & 20.09 & 12.22 & - \\
\hline & Co-Fe-rich & $\mathrm{BCC}(\mathrm{A} 2 / \mathrm{B} 2)$ & 11.94 & 19.77 & 16.18 & 19.41 & 15.99 & 16.72 & - \\
\hline & Nominal composition & - & 16.67 & 16.67 & 16.67 & 16.67 & 16.66 & - & 16.66 \\
\hline \multirow[t]{4}{*}{ AlCoCuFeNiTi (III) } & $\mathrm{Cu}$-rich & FCC & 8.33 & 6.71 & 48.86 & 15.83 & 14.93 & - & 5.35 \\
\hline & Al-Ni-rich & $\mathrm{BCC}(\mathrm{A} 2 / \mathrm{B} 2)$ & 20.38 & 16.01 & 9.6 & 16.29 & 19.97 & - & 17.75 \\
\hline & Al-Co-Ni-Ti-rich & $\mathrm{BCC}(\mathrm{A} 2 / \mathrm{B} 2)$ & 21.93 & 19.87 & 6.55 & 14.75 & 18.50 & - & 18.40 \\
\hline & Nominal composition & - & 14.29 & 14.29 & 14.28 & 14.28 & 14.28 & 14.29 & 14.29 \\
\hline \multirow[t]{3}{*}{ AlCoCuFeNiCrTi (IV) } & $\mathrm{Cu}$-rich & FCC & 6.52 & 2.15 & 77.91 & 3.57 & 6.34 & 1.65 & 1.86 \\
\hline & $\mathrm{Fe}-\mathrm{Cr}$-rich & FCC & 2.55 & 9.47 & 7.13 & 33.83 & 7.11 & 30.76 & 9.14 \\
\hline & Al-Ni-Ti-rich & $\mathrm{BCC}(\mathrm{A} 2 / \mathrm{B} 2)$ & 20.08 & 16.35 & 7.55 & 8.64 & 22.30 & 3.29 & 21.77 \\
\hline
\end{tabular}


Table 3. Predicted diffusion constants of AlCoCuFeNiCrTi at $\mathrm{T}=2,073 \mathrm{~K}$.

\begin{tabular}{cccccccc}
\hline Element & $\mathrm{Al}$ & $\mathrm{Co}$ & $\mathrm{Cu}$ & $\mathrm{Fe}$ & $\mathrm{Ni}$ & $\mathrm{Cr}$ & $\mathrm{Ti}$ \\
\hline $\mathrm{D}_{\mathrm{o}}\left[10^{-5} \mathrm{~cm}^{2} / \mathrm{s}\right]$ & $3.89 \pm 0.03$ & $4.04 \pm 0.02$ & $4.32 \pm 0.03$ & $3.65 \pm 0.03$ & $4.69 \pm 0.02$ & $3.76 \pm 0.05$ & $3.57 \pm 0.04$ \\
\hline
\end{tabular}


Table 4. Mechanical properties of as-cast alloys

\begin{tabular}{lcccccc}
\hline Sample & $\sigma_{f}(\mathrm{MPa})$ & $\sigma_{0.2}(\mathrm{MPa})$ & $E(\mathrm{GPa})$ & $\varepsilon_{f}(\%)$ & $H V$ & $n$ \\
\hline AlCoCuFeNi ( I ) & $1,452 \pm 5$ & $1,060 \pm 4$ & $202 \pm 6$ & $19.1 \pm 0.5$ & $387 \pm 5$ & 0.458 \\
\hline AlCoCuFeNiCr ( II ) & $1,857 \pm 8$ & $1,285 \pm 6$ & $219 \pm 5$ & $24.6 \pm 0.7$ & $459 \pm 6$ & 0.536 \\
\hline AlCoCuFeNiTi (III) & $1,816 \pm 6$ & $1,612 \pm 7$ & $231 \pm 7$ & $12.8 \pm 0.3$ & $623 \pm 8$ & 0.414 \\
\hline AlCoCuFeNiCrTi (IV) & $1,588 \pm 7$ & $1,523 \pm 5$ & $239 \pm 5$ & $8.1 \pm 0.2$ & $510 \pm 5$ & 0.455 \\
\hline
\end{tabular}


Table 5. Dynamic parameters derived from the potentiodynamic polarization curves by linear fitting

\begin{tabular}{ccccccc}
\multicolumn{7}{c}{ at $298 \mathrm{~K}$ and $366 \mathrm{~K}$} \\
\hline Sample & \multicolumn{2}{c}{$\mathrm{E}_{\text {corr }}(\mathrm{V}$ vs SCE $)$} & $\mathrm{i}_{\text {corr }}\left(\mu \mathrm{A} / \mathrm{cm}^{2}\right)$ & $\mathrm{R}_{\mathrm{p}}(\Omega)$ \\
\cline { 2 - 7 } & $298 \mathrm{~K}$ & $366 \mathrm{~K}$ & $298 \mathrm{~K}$ & $366 \mathrm{~K}$ & $298 \mathrm{k}$ & $366 \mathrm{k}$ \\
\hline AlCoCuFeNi ( I ) & -0.058 & -0.158 & 7.93 & 11.74 & 2273.5 & 1311.5 \\
AlCoCuFeNiCr ( II ) & -0.075 & -0.284 & 5.09 & 779.2 & 14450.3 & 29.2 \\
AlCoCuFeNiTi (III) & -0.253 & -0.374 & 44.76 & 3379 & 1144.9 & 36.0 \\
AlCoCuFeNiCrTi (IV) & -0.256 & -0.368 & 39.59 & 2246 & 1558.2 & 27.3 \\
\hline
\end{tabular}



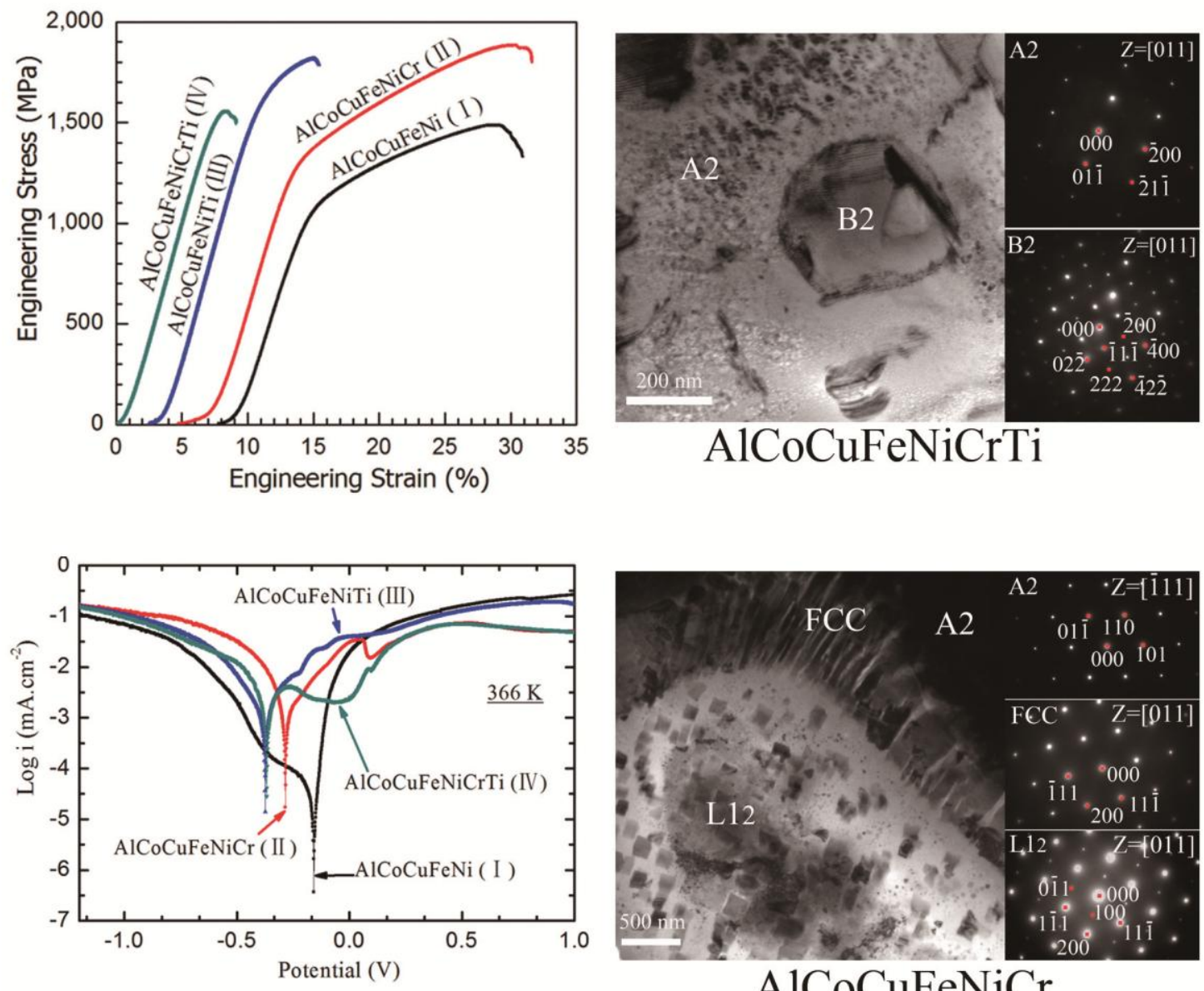

$\mathrm{AlCoCuFeNiCr}$ 